\title{
RESEARCH
}

Open Access

\section{Influence of platelet storage time on human platelet lysates and platelet lysate- expanded mesenchymal stromal cells for bone tissue engineering}

Siddharth Shanbhag ${ }^{1}$, Samih Mohamed-Ahmed ${ }^{1}$, Turid Helen Felli Lunde², Salwa Suliman' ${ }^{1}$, Anne Isine Bolstad ${ }^{1}$, Tor Hervig ${ }^{2,3,4}$ and Kamal Mustafa ${ }^{*^{*}}$

\begin{abstract}
Background: Human platelet lysate (HPL) is emerging as the preferred xeno-free supplement for the expansion of mesenchymal stromal cells (MSCs) for bone tissue engineering (BTE) applications. Due to a growing demand, the need for standardization and scaling-up of HPL has been highlighted. However, the optimal storage time of the source material, i.e., outdated platelet concentrates (PCs), remains to be determined. The present study aimed to determine the optimal storage time of PCs in terms of the cytokine content and biological efficacy of HPL.

Methods: Donor-matched bone marrow (BMSCs) and adipose-derived MSCS (ASCS) expanded in HPL or fetal bovine serum (FBS) were characterized based on in vitro proliferation, immunophenotype, and multi-lineage differentiation. Osteogenic differentiation was assessed at early (gene expression), intermediate [alkaline phosphatase (ALP) activity], and terminal stages (mineralization). Using a multiplex immunoassay, the cytokine contents of HPLs produced from PCs stored for 1-9 months were screened and a preliminary threshold of 4 months was identified. Next, HPLs were produced from PCs stored for controlled durations of $0,1,2,3$, and 4 months, and their efficacy was compared in terms of cytokine content and BMSCs' proliferation and osteogenic differentiation.

Results: BMSCs and ASCs in both HPL and FBS demonstrated a characteristic immunophenotype and multi-lineage differentiation; osteogenic differentiation of BMSCs and ASCs was significantly enhanced in HPL vs. FBS. Multiplex network analysis of HPL revealed several interacting growth factors, chemokines, and inflammatory cytokines. Notably, stem cell growth factor (SCGF) was detected in high concentrations. A majority of cytokines were elevated in HPLs produced from PCs stored for $\leq 4$ months vs. $>4$ months. However, no further differences in PC storage times between 0 and 4 months were identified in terms of HPLs' cytokine content or their effects on the proliferation, ALP activity, and mineralization of BMSCs from multiple donors.

(Continued on next page)
\end{abstract}

\footnotetext{
*Correspondence: kamal.mustafa@uib.no

'Department of Clinical Dentistry, Faculty of Medicine, University of Bergen, Årstadveien 19, 5008 Bergen, Norway

Full list of author information is available at the end of the article
}

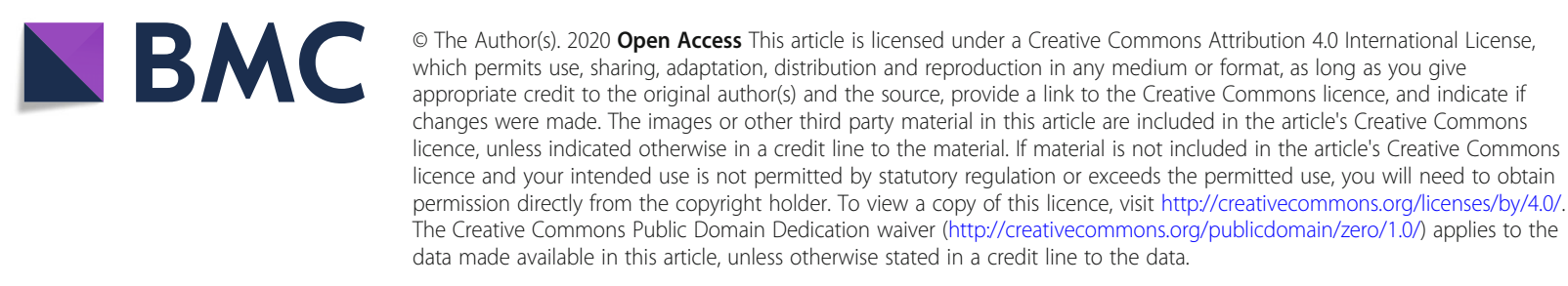




\begin{abstract}
(Continued from previous page)
Conclusions: MSCs expanded in HPL demonstrate enhanced osteogenic differentiation, albeit with considerable donor variation. HPLs produced from outdated PCs stored for up to 4 months efficiently supported the proliferation and osteogenic differentiation of MSCs. These findings may facilitate the standardization and scaling-up of HPL from outdated PCs for BTE applications.
\end{abstract}

Keywords: Platelet lysate, Mesenchymal stromal cells, Bone tissue engineering, Regenerative medicine

\section{Background}

Adult mesenchymal stromal cells (MSCs) from various tissue sources, most frequently bone marrow (BMSCs) and adipose tissue (ASCs), are increasingly being used in bone tissue engineering (BTE) strategies for reconstruction of clinically challenging bone defects [1]. Although the use of whole tissue fractions, such as bone marrow concentrates and adipose stromal vascular fractions (SVFs), offers the feasibility of minimum cell manipulation and cost-effectiveness, the yield of MSCs obtained is relatively low. MSCs represent $<1 \%$ of the mononuclear cell fraction in the bone marrow and approximately $1.4 \%$ in adipose SVF [2]. This has encouraged ex vivo expansion strategies, which aim to exponentially amplify the number of BMSCs or ASCs available for implantation and thereby improve clinical outcomes.

The use of safe, standardized, and efficacious culture conditions is a critical aspect of Good Manufacturing Practice (GMP)-grade MSC expansion. Supplements providing growth factors (GFs), proteins, and enzymes for ex vivo MSC expansion are broadly categorized as xenogeneic (animal-derived), xeno-free (human-derived), or chemically defined [3,4]. Although fetal bovine serum (FBS) is commonly used for MSC expansion [5], several limitations of FBS supplementation have been highlighted $[3,6]$. European guidelines advocate the use of "non-ruminant" over "ruminant materials" for the manufacture of human medicinal products [7]. Accordingly, an increase in the use of "xeno-free" supplements, such as human platelet lysate (HPL), to develop GMP-compliant MSC expansion protocols has recently been reported $[4,8]$.

HPL is defined as a cell-free, protein- and GF-rich biological material produced from platelet concentrates (PCs) initially intended for transfusion [9]. Platelets release a wide range of physiological GFs and cytokines, which can significantly enhance cell growth and function. Pooledand/or single-donor apheresis PCs are routinely prepared by blood establishments for transfusion and, depending on local regulations, stored for a maximum of 4-7 days before being discarded [9]. It is estimated that $5-20 \%$ of PCs produced in transfusion centers become "outdated" and utilizing these for HPL production is reported to be an ethically and economically optimal strategy, due to comparable efficacy of HPL produced from "fresh" and outdated PCs [6]. The current literature consistently demonstrates that HPL is at least comparable, and often superior, to FBS in supporting MSC proliferation, stromal phenotype, chromosomal stability, and multi-lineage differentiation potential [10]. Interestingly, MSCs expanded in HPL have been reported to demonstrate enhanced osteoblastic differentiation potential, suggesting particular benefits of HPL expansion for BTE applications [4]. A clinically validated protocol for MSC expansion in HPL for BTE applications has recently been published [11].

The importance of HPL in GMP-grade MSC production is highlighted by the publication of several recent consensus statements $[9,12-14]$. The most common themes in these reports are the need to scale-up HPL production by blood establishments and, more urgently, the need for standardization of HPL products. There is currently considerable large variation in the methods used to produce HPL, which is further complicated by the availability of several inadequately defined commercial HPL products. A need for standardization has been described at various levels of the HPL production process, such as the source material (pooled buffy coats vs. apheresis PCs and fresh vs. outdated PCs) and storage medium [plasma vs. platelet additive solution (PAS) or a combination]. Moreover, the pool sizes, i.e., the number of $\mathrm{PC}$ units or individual donations that are pooled to produce a single HPL product, method of platelet lysis, use of pathogen inactivation strategies, and quality control/release criteria for the final product vary between manufacturers [14].

Nevertheless, there is a clear consensus that the use of outdated pooled PCs as the source material is the optimal strategy for large-scale HPL production. Although the storage time of PCs varies between blood centers based on national regulations, recent recommendations call for immediate freezing of outdated PCs, i.e., within 7 days after collection, for subsequent HPL productionthis represents an efficient use of resources and minimizes waste [9]. However, for many blood centers, it may not always be possible to initiate HPL production on the day of (or soon after) PC expiry, and the maximum duration for which PCs can be stored before being used to prepare an efficient HPL remains unknown. If outdated PCs can be stored for a standardized period to produce an optimal HPL product, it would facilitate logistical solutions and encourage more blood establishments to incorporate HPL production into their protocols. Thus, optimizing the storage time of PCs 
would be a step towards addressing both the standardization and scaling-up of HPL production.

In the context of BTE, a recent study demonstrated differential effects of commercial HPL products on the mineralization capacity of BMSCs, although the mechanisms and HPL components contributing to these differences were not studied [15]. It would be of interest to investigate the effects of PC storage times on the cytokine contents of HPL, and subsequently the proliferation kinetics and osteogenic differentiation potential of HPLexpanded MSCs. Therefore, the objectives of this study were to characterize HPL in terms of its cytokine content and efficacy for MSC expansion (vs. FBS), particularly for BTE applications, and to investigate the effect of PC storage time on the cytokine content and efficacy of HPL in terms of MSC proliferation and osteogenic differentiation.

\section{Materials and methods Production of HPL PC preparation and storage}

The HPL herein (Bergenlys ${ }^{\bullet}$, Bergen, Norway) is prepared from outdated pooled whole blood-derived PCs. The PCs are prepared at the Department of Immunology and Transfusion Medicine, Haukeland University Hospital, Bergen, Norway, according to established procedures and in line with national and EU quality requirements. Briefly, written informed consent is obtained from volunteer, healthy blood donors (aged 1870 years) complying with national guidelines for blood donation. Whole blood is processed with the Reveos Automated Blood Processing Unit (Terumo BCT, Lakewood, CO, USA). All donations are tested for $\mathrm{ABO}$ and RhD blood groups, infectious disease markers (HIV1/2, HBV, HCV), and sterility (aerobic bacteria). Donor information and manufacturing details are stored to ensure traceability of the final product. PCs $(\sim 300 \mathrm{~mL})$ are generated by manually pooling five interim platelet units (IPUs) in 30\% plasma and 70\% platelet additive solution (Terumo BCT) and subsequently leukocyte-filtered (Immuflex ${ }^{\circ}$, Terumo BCT). Pooled PCs containing $>2 \times$ $10^{11}$ platelets (and $<1 \times 10^{6}$ leukocytes) are $\mathrm{X}$-ray irradiated at a dose of $25 \mathrm{~Gy}$ and stored at $22^{\circ} \mathrm{C} \pm 2{ }^{\circ} \mathrm{C}$ under agitation for no longer than 7 days for use as transfusion units. All unused (or outdated) 7-day-old PCs are frozen at $-80^{\circ} \mathrm{C}$ within $24 \mathrm{~h}$ for subsequent HPL production.

\section{HPL production}

Unused 7-day-old PCs were used for HPL production via the freeze/thaw lysis method [16]. Briefly, four different PCs (each PC containing buffy coats from five donors $=4 \times 5=20$ donors per HPL product) were exposed to multiple freezing $\left(-80^{\circ} \mathrm{C}\right.$ for at least $\left.3 \mathrm{~h}\right)$ and thawing cycles $\left[+37^{\circ} \mathrm{C}\right.$ in a plasma thawer (Plasmatherm,
Barkey GmbH Co. KG, Leoppoldshoehe, Germany) for $15 \mathrm{~min}$ ] to ensure platelet lysis before pooling. Pooled PCs were then centrifuged at $3000 \times g\left(4{ }^{\circ} \mathrm{C}, 15 \mathrm{~min}\right)$ to remove platelet fragments and aliquoted as the final HPL product. No fibrinogen depletion step was performed. HPL aliquots were stored at $-80^{\circ} \mathrm{C}$ and thawed overnight at $4{ }^{\circ} \mathrm{C}$ for subsequent use in experiments.

\section{Cell culture with HPL}

Isolation and expansion of donor-matched BMSCs and ASCs The biological efficacy of HPL was tested in various cellular assays using human BMSCs and ASCs. Donormatched BMSCs and ASCs were isolated and expanded according to established protocols [17]. Briefly, human adipose tissue and bone marrow aspirates were obtained after informed parental consent and ethical approval (2013-1248/Regional Ethical Committee, South East, Norway) from patients aged 8-14 years undergoing surgery at the Department of Plastic Surgery, Haukeland University Hospital. For each donor, BMSCs and ASCs were isolated in 5\% HPL and 10\% FBS (GE Healthcare, South Logan, UT, USA) supplemented growth media [Dulbecco's modified Eagle's medium (DMEM, Invitrogen, Carlsbad, CA, USA) with 1\% antibiotics (penicillin/ streptomycin; GE Healthcare)]. In HPL-supplemented media, $1 \mathrm{IU} / \mathrm{mL}$ of heparin was added to prevent gelation and the medium was sterile filtered $(0.2 \mu \mathrm{m})$ before use. Cells were sub-cultured and expanded according to a clinically validated protocol with a seeding density of 4000 cells $/ \mathrm{cm}^{2}$ [11]; passage $2-4$ cells from at least three different donors were used in experiments. Cell number and viability were assessed using $0.4 \%$ Trypan blue stain (Invitrogen) and a Countess ${ }^{\circ}$ Automated Cell Counter (Invitrogen).

\section{Immunophenotype of BMSCs and ASCs}

The immunophenotype of BMSCs and ASCs in HPL and FBS was assessed by flow cytometry based on the expression of specific surface antigens, as previously described [17] according to the "minimal criteria" for defining MSCs [18]. Briefly, the cells in HPL and FBS were incubated with conjugated antibodies against selected "negative" (CD34, CD45, HLA-DR) and "positive" (CD73, CD90, CD105) MSC markers (all from BD Biosciences, San Jose, CA, USA) and STRO-1 (Santa Cruz Biotechnology, Dallas, TX, USA) following the manufacturers' recommendations. Quantification was performed with a BD LSR Fortessa cell analyzer (BD Biosciences), and data were analyzed using flow cytometry software (FlowJo V10, Flowjo, LLC, Ashland, OR, USA).

\section{Cell proliferation based on DNA quantification}

BMSCs and ASCs in HPL and FBS were seeded in 24well plates at a density of 4000 cells $/ \mathrm{cm}^{2}$. After 1,7 , and 
14 days of culture, DNA quantification was performed using the Quant-IT ${ }^{\oplus}$ PicoGreen dsDNA Assay Kit (Thermo Fisher Scientific, Carlsbad, CA, USA) according to the manufacturer's instructions. Briefly, cells were lysed in $0.1 \%$ Triton X-100 and the PicoGreen staining solution was added and incubated for $5 \mathrm{~min}$ at RT protected from light, before fluorescence was measured at $480 \mathrm{~nm}(\mathrm{Ex}) / 520 \mathrm{~nm}(\mathrm{Em})$ with a microplate reader. DNA concentrations $(\mathrm{ng} / \mathrm{mL})$ were calculated based on known standards.

\section{Multi-lineage differentiation of BMSCs and ASCs}

The ability of BMSCs and ASCs to differentiate into multiple stromal lineages was tested as previously described [17]. Briefly, for adipogenic differentiation, cells in HPL and FBS were cultured in StemPro adipogenic differentiation medium (Invitrogen) or standard growth medium (control). After 14 days, intracellular lipid formation was assessed via Oil red O (Sigma-Aldrich) staining. For quantification, the stain was extracted using 99\% isopropanol (Sigma-Aldrich) and absorbance was measured at $540 \mathrm{~nm}$ using a microplate reader. For osteogenic differentiation, cells in HPL and FBS were cultured in osteogenic differentiation medium prepared by adding final concentrations of $0.05 \mathrm{mM} \mathrm{L}$-ascorbic acid 2-phosphate, $10 \mathrm{nM}$ dexamethasone, and $10 \mathrm{mM} \beta$ glycerophosphate (all from Sigma-Aldrich) to the respective growth media. Cells in standard growth medium served as controls. After 21 days, extracellular calcium deposition was evaluated via Alizarin red $\mathrm{S}$ staining (Sigma-Aldrich). For quantification, the stain was dissolved in cetylpyridinium chloride (Sigma-Aldrich) and absorbance was measured at $540 \mathrm{~nm}$ using the microplate reader.

\section{Gene expression}

After 7 days of osteogenic induction, the expression of osteogenesis-related genes (Supplementary Table 1) was assessed in BMSCs and ASCs in HPL and FBS via quantitative real-time polymerase chain reaction (qPCR) using TaqMan $^{\circ}$ real-time PCR assays (Thermo Fisher Scientific). RNA extraction and cDNA synthesis were performed as previously described [17]. The expressions of the genes of interest were normalized to that of glyceraldehyde 3phosphate dehydrogenase (GAPDH). Data were analyzed by the $\Delta \Delta C t$ method, and results are presented as fold changes in HPL groups relative to FBS groups.

\section{Alkaline phosphatase (ALP) activity}

After 7 and 14 days, ALP activity in the cells was measured using the SIGMAFAST BCIP/NBT assay (SigmaAldrich). Following manufacturer's instructions, cells were lysed in $0.1 \%$ Triton-X100 buffer, mixed with a working solution containing a phosphatase substrate and alkaline buffer solution, and incubated at $37^{\circ} \mathrm{C}$ for 15 min, and absorbance was measured at $405 \mathrm{~nm}$ using a microplate reader.

\section{Cytokine content in HPL Multiplex assay and cytokine network analysis}

The concentrations of 48 cytokines (Supplementary Table 2) in HPL were measured using a multiplex immunoassay-Bio-Plex ${ }^{\circ}$ Pro 48-plex Human Cytokine Screening Panel (Bio-Rad Laboratories, CA, USA) and a Bio-Plex 200 System (Bio-Rad), according to the manufacturer's instructions. The cytokines included various GFs, inflammatory mediators, and chemokines involved in regulating MSC growth and function. To validate the multiplex data, concentrations of three selected GFs, namely platelet-derived growth factor BB (PDGF-BB), transforming growth factor- $\beta 1$ (TGF- $\beta 1$ ), and vascular endothelial growth factor (VEGF), were measured in representative batches of HPL via enzyme-linked immunosorbent assay (ELISA) kits (R\&D Diagnostics, Wiesbaden, Germany) following the manufacturer's protocols. Interactions between cytokines were analyzed using the Search Tool for the Retrieval of Interacting Genes/Proteins (STRING) database and online software [19]. Cytokines were clustered according to the Markov Cluster algorithm and the STRING global score as previously reported [20].

\section{Screening of different storage times to identify a threshold}

The first multiplex assay included several HPL batches produced from PCs with different storage times (range 19 months). These HPLs, and corresponding PC units, were identified and screened retrospectively from a biobank, i.e., not collected and intentionally frozen for specific periods of time (as performed later in the study). In order to determine whether the duration of frozen storage of PCs affects the cytokine content of subsequently produced HPL, the storage times were divided into two categories: storage $\leq 4$ months and $>4$ months. Categorization was based on (a) recommendations regarding "quarantine storage" of GMP-grade blood products which state that the product must only be released if the donors have been tested negative for transmissible diseases twice, i.e., at the time of blood donation and re-tested as negative 4 months (or longer) thereafter $[13,21]$, and (b) current practices at the HPL production site (Haukeland Hospital Bloodbank), which are in line with the above recommendations.

\section{Identifying a specific threshold for PC storage time}

Since a preliminary threshold of 4 months was identified in the screening assay, a more focused custom-designed multiplex assay with 16 selected cytokines was performed to identify a specific threshold, if any, between 0 and 4 months. For this purpose, HPL batches were 
specially produced from PCs frozen for controlled durations of $1,2,3$, and 4 months. A reference HPL batch of PCs frozen and processed immediately ("0 months") was also included. The custom assay was a modification of the 48-plex panel (Bio-Rad) previously described. For both multiplex assays, data was analyzed using the BioPlex Manager Software (Bio-Rad) and final cytokine concentrations were derived in $\mathrm{pg} / \mathrm{mL}$.

\section{Effect of frozen PC storage time on HPL efficacy MSC morphology and proliferation kinetics}

To investigate whether PC storage times affected the biological performance of HPL, cellular assays were performed using BMSCs. Previously cryopreserved passage 1 BMSCs were expanded for three additional passages in HPL produced from 0-, 1-, 2-, 3-, or 4-month PCs. At approximately $80 \%$ sub-confluence, cells from all conditions were harvested, counted, and re-seeded at 4000 cells $/ \mathrm{cm}^{2}$, following the same clinically validated protocol [11]. The population doubling (PD) rate was determined using the following formula [22]:

$$
X=\frac{\log 10\left(N_{H}\right)-\log 10\left(N_{1}\right)}{\log 10(2)}
$$

$N_{H}$ is the harvested cell number and $N_{1}$ is the plated cell number. The PD for each passage was calculated and added to the PD of the previous passages to generate data for cumulative population doublings (CPD). Additionally, the population doubling time (PDT), i.e., the average time between two doublings, was calculated using the following formula [22]:

$$
X=\frac{\log 2 \times \Delta t}{\log 10\left(N_{H}\right)-\log 10\left(N_{1}\right)}
$$

\section{MSC osteogenic differentiation}

To investigate whether PC freezing times affected the osteogenic differentiation potential of BMSCs, cells expanded for two passages with HPL produced from 0-, 1-, 2-, 3-, or 4-month PCs were plated for osteogenic differentiation assays. The differentiation medium was prepared by adding osteogenic supplements (as described above) to the respective growth media. Osteogenic differentiation was assessed via an ALP assay after 7 and 14 days (as described above) and via Alizarin red S staining of extracellular calcium deposits after 21 days (as described above) in osteogenically induced and noninduced BMSCs. Additionally, quantification of DNA per sample in the ALP experiment was performed as previously described. ALP activity was normalized to the amount of DNA per corresponding sample (ng/mL).

\section{Statistical analysis}

Statistical analyses were performed using the IBM SPSS version 17.0 software package (SPSS Inc., Chicago, IL, USA). Data are represented as arithmetic means \pm SD, unless specified. For gene expression, statistical analyses are based on delta-Ct values and data are presented as relative fold changes. The student $t$ test and one-way analysis of variance (ANOVA), followed by a post hoc Tukey's test for multiple comparisons, were applied when appropriate and $p<0.05$ was considered statistically significant.

\section{Results}

\section{Characterization of HPL efficacy}

Isolation and characterization of BMSCs and ASCs

Donor-matched BMSCs and ASCs demonstrating characteristic plastic adherence and fibroblastic morphology were successfully expanded in both HPL- and FBSsupplemented media. Distinct morphological differences were observed between cells in HPL and FBS-the former being smaller and more spindle-shaped; these differences were more apparent at earlier passages (Fig. 1a). BMSCs and ASCs in both HPL and FBS demonstrated the characteristic MSC phenotype, i.e., >95\% of the cells were positive for the stromal markers CD73, CD90, and CD105, while $<5 \%$ of the cells expressed HLA-DR or the hematopoietic markers CD34 and CD45 (Fig. 1b, Supplementary figure 1). A trend for higher expression of STRO1 was observed in HPL-cultured BMSCs and ASCs (Fig. 1c). Cell proliferation over 14 days was significantly greater in HPL-cultured BMSCs and ASCs based on DNA quantification (Fig. 1c).

\section{Multi-lineage differentiation of BMSCs and ASCs}

BMSCs and ASCs in both HPL- and FBS-supplemented media demonstrated the capacity to differentiate into adipocytes and osteoblasts, with some differences. Osteogenic differentiation in HPL and FBS was assessed at the gene, protein, and functional levels. Expression of early osteogenesis-related genes RUNX2 and BMP2 was significantly upregulated in HPL-cultured BMSCs and ASCs after 7 days (Fig. 3a). Interestingly, expressions of SPP1 and BGLAP, typically associated with later stages of osteogenesis, were also upregulated in HPL-cultured cells; BGLAP was significantly upregulated in ASCs. Intracellular ALP activity after 7 and 14 days was higher in HPL- vs. FBS-cultured BMSCs and ASCs; these differences were more pronounced in ASCs (Fig. 3b). While BMSCs generally presented higher ALP activity compared to ASCs at 7 days, the activity at 14 days was comparable between the two cell types. Significantly greater mineral deposition via Alizarin red $\mathrm{S}$ staining was observed in HPL- vs. FBS-cultured BMSCs and ASCs after 21 days, suggesting an enhanced osteogenic differentiation capacity of these cells (Fig. 3c). A trend for superior 

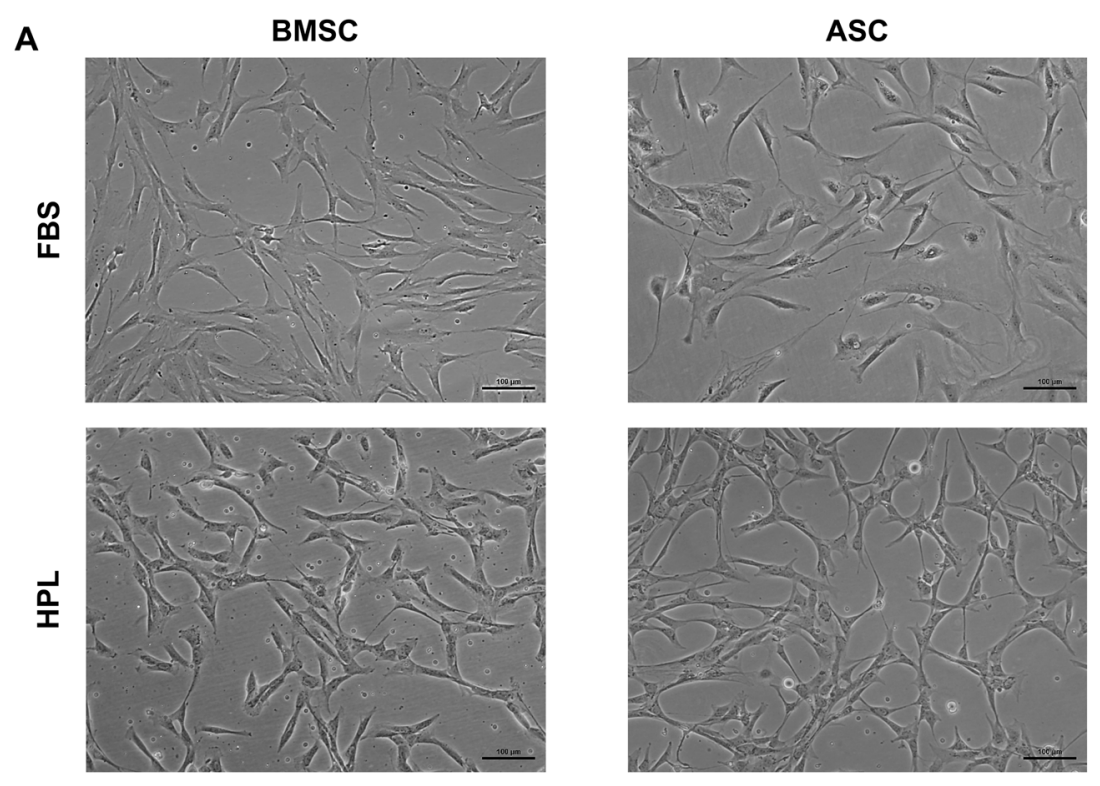

B

BMSC

ASC
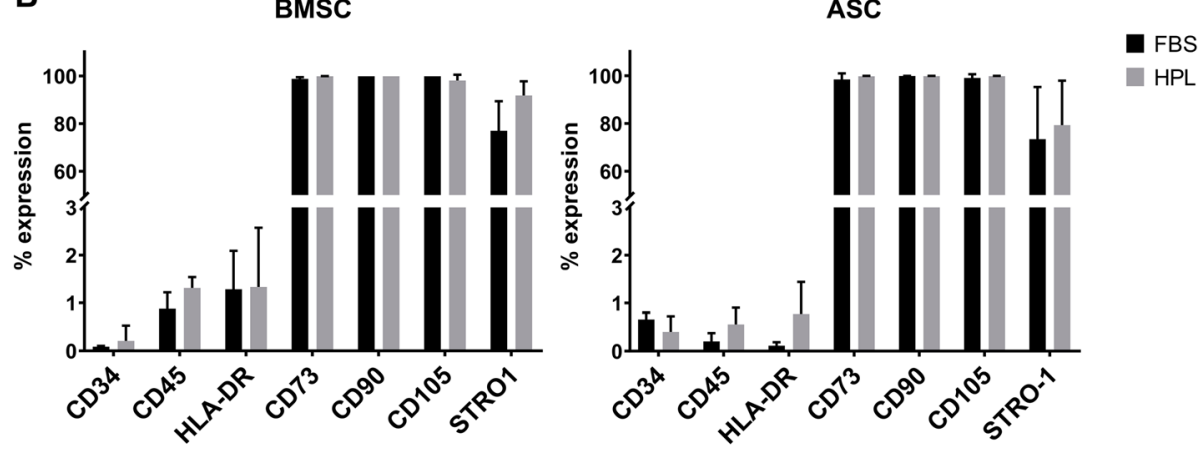

C

BMSC
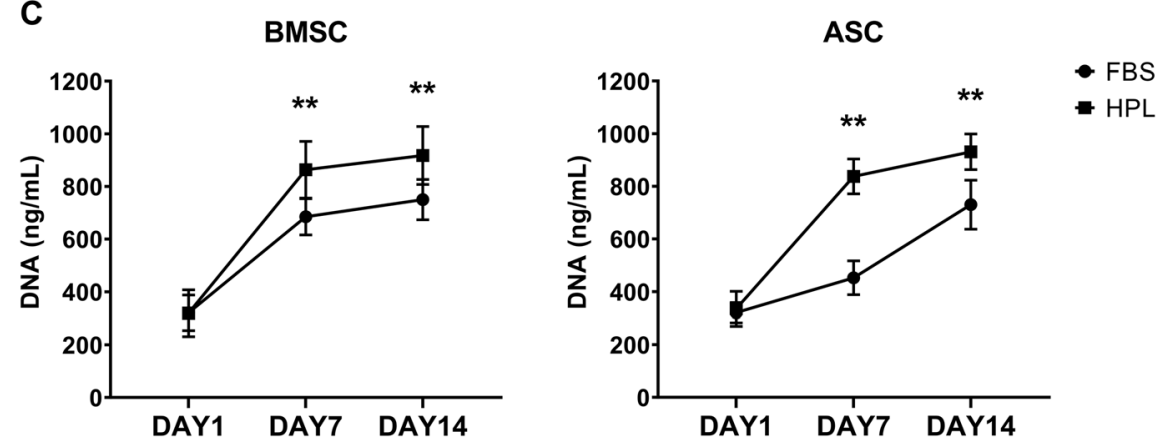

Fig. 1 Characterization of BMSCs and ASCs in HPL. a Morphology of BMSCs and ASCs from one representative donor (scale bar $100 \mu \mathrm{m}$ ). b Surface marker expression of BMSCs and ASCs based on flow cytometry; data represent means \pm SD ( $n=3$ donors). $\mathbf{c}$ Proliferation of BMSCs and ASCs over 14 days based on DNA quantification; data represent means \pm SD ( $n=3$ donors); ${ }^{* *} p<0.001$

mineralization was observed in BMSCs as compared to ASCs. After 14 days of induction, ASCs demonstrated superior adipogenic differentiation, i.e., greater accumulation of intracellular lipid vesicles, compared to BMSCs, as revealed by quantification of Oil red $\mathrm{O}$ staining (Fig. 2e). HPLcultured ASCs and BMSCs demonstrated similar adipogenic differentiation vs. their FBS-cultured counterparts (Fig. 2f).
No adipogenic or osteogenic differentiation of cells was observed in the standard growth media (data not shown).

\section{Characterization of HPL cytokine content} Multiplex assay and cytokine network analysis

A multiplex immunoassay was performed using HPLs produced from frozen PCs stored for 1-9 months. Thirty 


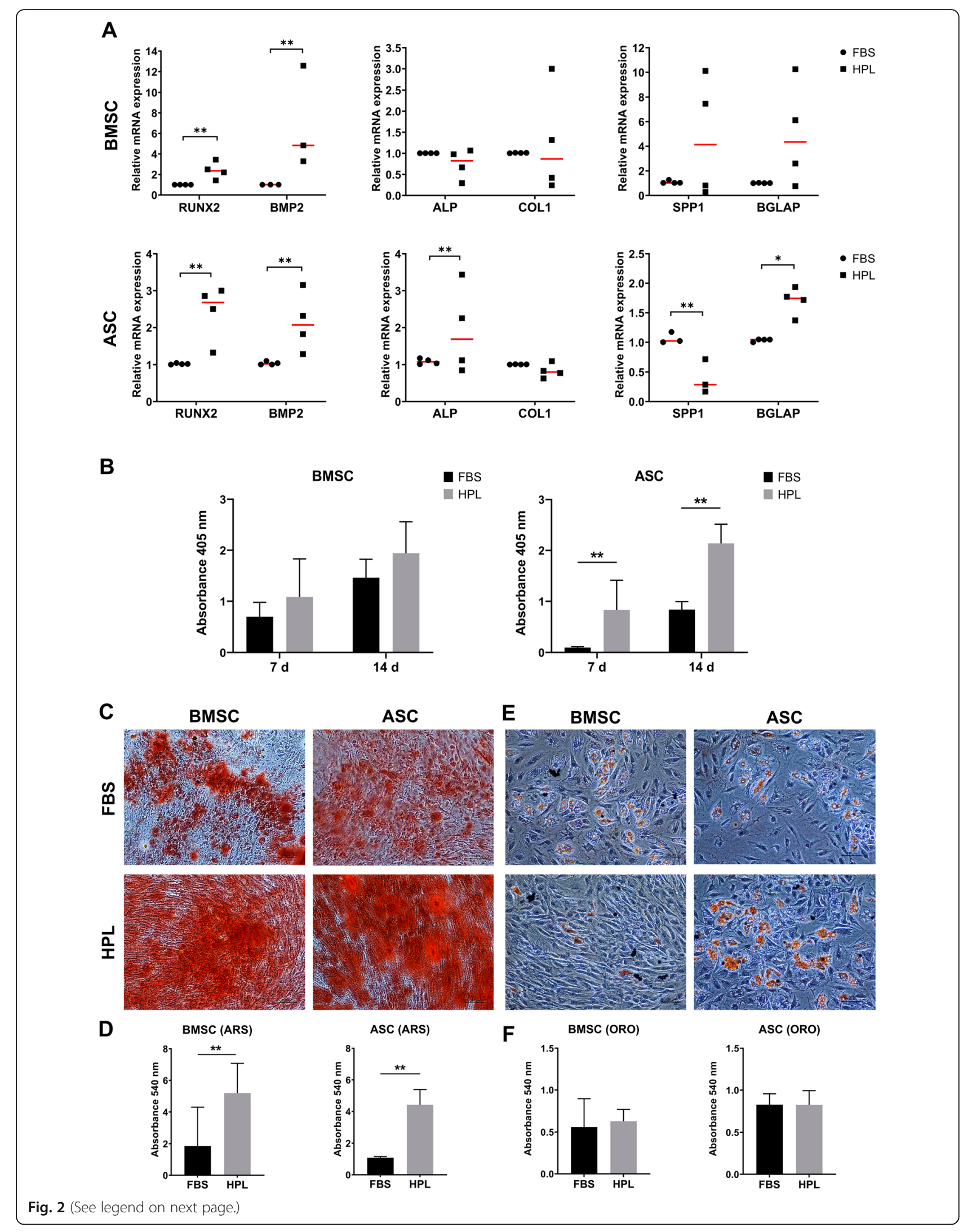


(See figure on previous page.)

Fig. 2 Multi-lineage differentiation of BMSCs and ASCs in HPL. a Osteogenic differentiation: relative expression (fold changes) of early, intermediate, and late osteogenic gene markers in BMSCs and ASCs after 7 days of induction. Data represent means; each symbol represents a single donor ( $n=\geq 3$ donors) based on the average of $\geq 2$ experimental replicates; statistical analyses are based on delta-Ct values; ${ }^{*} p<0.05 ;{ }^{* *} p<0.001$. b ALP activity in BMSCs and ASCs after 7 and 14 days of osteogenic induction. Data represent means \pm SD ( $n=3$ donors); ** $p<0.001$. Representative images of Alizarin Red S (ARS) staining (c) and quantification (d) after 21 days. e Adipogenic differentiation: representative images of Oil red $\mathrm{O}(\mathrm{ORO})$ staining and quantification (f) after 14 days. Scale bars $100 \mu \mathrm{m}$. Data represent means \pm SD $\left(n=3\right.$ donors); ${ }^{*} p<0.001$

of the 48 cytokines tested, including various GFs $(n=$ $11)$, chemokines $(n=9)$, and inflammatory mediators $(n=10)$, were reliably detected in all tested HPLs. Cytokine concentrations, in comparison to previous studies, are reported in Table 1 . Concentrations of three selected GFs, i.e., PDGF-BB, TGF-1, and VEGF, were validated via ELISA (Supplementary figure 2). The cytokine network analysis identified two major clusters of GFs, and chemokine/inflammatory mediators; stem cell growth factor (SCGF/CLEC11A) and stem cell factor (SCF/ KITLG) were clustered separately (Fig. 3). Clear and abundant interactions were identified between the clusters including synergistic relations between several proteins that contribute to MSC proliferation, chemotaxis, and osteogenic differentiation.

\section{Screening of different storage times to identify a threshold}

Of these 30 cytokines, the concentrations of 27 cytokines were significantly reduced in the $>4$-month group while only one cytokine, i.e., regulated upon activation, normal $\mathrm{T}$ cell expressed and secreted (RANTES), was significantly increased vs. the $\leq 4$-month group. In addition to the known predominant cytokines PDGF-BB and TGF$\beta 1$, high levels of SCGF and macrophage inhibitory factor (MIF) were detected in HPL. Other GFs, such as basic fibroblast growth factor (b-FGF), hepatocyte growth factor (HGF), SCF, VEGF, and all inflammatory mediators [various interleukins (IL), tumor necrosis factor- $\alpha$ (TNF- $\alpha)$, and TNF- $\beta$ ] were present in relatively lower concentrations (Fig. 4).

\section{Identifying a specific threshold for PC storage time}

After a preliminary threshold of 4 months was identified, a second multiplex immunoassay with 16 selected cytokines was performed to identify a specific threshold, if any, for cytokine degradation between 0 and 4 months. Significantly lower concentrations were detected at 0 and 1 months for SCF and at 2 months for GCSF (Fig. 5). No significant differences were observed between the different storage times for any of the other tested cytokines, and no definitive threshold below 4 months could be identified.

\section{Effect of frozen PC storage time on HPL efficacy MSC morphology and proliferation kinetics}

PC storage time did not seem to affect the biological performance of HPL; no differences in BMSC morphology were observed between the different storage times over three serial passages (Fig. 6a). The proliferation data revealed lower PD rate (fewer doublings) and higher PDT with increasing passages. No significant differences were observed with regard to kinetics-related variables (PD, CPD, PDT) or absolute DNA amounts between the different $\mathrm{PC}$ storage times (Fig. 6b).

\section{MSC osteogenic differentiation}

To investigate whether PC storage times affected the osteogenic differentiation potential of BMSCs, ALP activity (7, 14 days) and mineralization (21 days) were assessed. When combining data from all donors, no significant differences in ALP (Fig. 7a) or mineralization (Fig. 7b) were observed between the different PC storage times. Considerable variation was observed between the different BMSC donors in all groups-a trend for higher mean ALP activity (at 7 days) and mineralization, with lower inter-donor variation, was observed in the 3month storage group. When analyzing data from individual donors, some differences in ALP activity and mineralization were observed, i.e., BMSCs from the same donor showed different activities in HPLs from different PC storage times, although these differences did not reach statistical significance for any of the donors. Overall, donor-related properties rather than PC storage time seemed to influence the osteogenic potential of HPLcultured BMSCs.

\section{Discussion}

HPL is emerging as the preferred xeno-free supplement for the GMP-grade expansion of MSCs for BTE applications [1, 11]. Accordingly, there is a growing need for standardization and scaling-up of HPL production [12, 14]. Current GMP guidelines call for HPL release criteria to include testing for specific cytokines and biological efficacy based on cellular assays [9, 12]. In the present study, a scalable and GMP-compliant HPL was produced based on previously published methods and characterized for its cytokine content and efficacy for MSC expansion. Consistent with previous reports, HPL supported the expansion, stromal phenotype, and multilineage, particularly osteogenic, differentiation of MSCs in comparison to FBS [17].

A strength of the present study was the comparison of donor-matched cells from two different tissue sources, 
Table 1 Multiplex-based measurements of cytokine concentrations $(\mathrm{pg} / \mathrm{mL})$ in HPL

\begin{tabular}{|c|c|c|c|c|c|c|c|}
\hline Reference & $(21)^{*}$ & (39) & (41) & $(42)$ & (43) & $(44)^{* *}$ & Present study \\
\hline $\begin{array}{l}\text { Starting } \\
\text { material }\end{array}$ & $<5 d B C$ or $A P$ & $<24 \mathrm{~h} \mathrm{AP}$ & Fresh BC & $\operatorname{Exp} B C$ & $\begin{array}{l}7 \mathrm{~d} B C(3 \mathrm{w} \text { at }-80 \mathrm{C}) \text {, pathogen } \\
\text { inactivated }\end{array}$ & $5-7 \mathrm{~d} \mathrm{BC}$ & $7 \mathrm{~d} \mathrm{BC}$ \\
\hline Donors (n) & $\begin{array}{l}<12(\mathrm{BC}) \text { or } 1 \\
(\mathrm{AP})\end{array}$ & 1 & 16 & $245+16$ & 16 & 40 & 20 \\
\hline Lysis method & $1-2 \times F / T$ & $2 \times F / T$ & $3 \times \mathrm{F} / \mathrm{T}$ & $1 \times F / T$ & $3 \times F / T$ & $3 \times \mathrm{F} / \mathrm{T}$ & $3 \times F / T$ \\
\hline Cytokines ( $n$ ) & 23 & 12 & 27 & 22 & 37 & 45 & 48 \\
\hline PDGF-AA & $239,412 \pm 53,690$ & & & $10,287+1820$ & $11,433.75+3083.45$ & & \\
\hline PDGF-AB/BB & $\begin{array}{l}571,730+381 \\
036\end{array}$ & $\begin{array}{l}1244+ \\
478.46\end{array}$ & $\begin{array}{l}13,534.4+ \\
326.9\end{array}$ & $27,407+5365$ & $25,941.5+1891.06$ & $11,121+1126$ & $\begin{array}{l}11,783.482+ \\
917.39\end{array}$ \\
\hline TGF- $\beta 1$ & $139,029+18,854$ & & & & & & $\begin{array}{l}306,801.77+81 \\
171.87\end{array}$ \\
\hline b-FGF & $495+27$ & $\begin{array}{l}77.09+ \\
21.33\end{array}$ & $256.6+7.6$ & & $407+105$ & $569+10$ & $56.48+9.85$ \\
\hline HGF & & & $\begin{array}{l}1594.7+ \\
172.3\end{array}$ & & & $2631+204$ & $542.39+42.21$ \\
\hline VEGF-A/D & $325+34$ & $\begin{array}{l}660.88+ \\
221.90\end{array}$ & $421.9+1.9$ & & $424.5+88.91$ & $\begin{array}{l}1742+133 / \\
398+60\end{array}$ & $440.175+40.35$ \\
\hline EGF & & & $754.9+89.9$ & & $997.5+825.58$ & $1104+224$ & \\
\hline IGF & & & & & & $1122+54$ & \\
\hline b-NGF & & $\begin{array}{l}85.55+ \\
24.27\end{array}$ & & & & $936+28$ & $19.05+9.29$ \\
\hline BDNF & & & & & & $3169+213$ & \\
\hline SCGF/CLEC11a & & & & & & & $\begin{array}{l}186,005.65+12 \\
463.91\end{array}$ \\
\hline SCF/KITLG & & & & & & $260+35$ & $30.45+4.35$ \\
\hline G-CSF & $74+19$ & & $131.4+9.4$ & & $40+15.36$ & & $108.68+13.17$ \\
\hline GM-CSF & $34+16$ & & $98.1+3.8$ & & $22+6.27$ & $2423+0$ & $7.42+2.28$ \\
\hline M-CSF & & & & $\begin{array}{l}129,689+14 \\
654\end{array}$ & & & $129.65+55.04$ \\
\hline MCP1/CCL2 & & $\begin{array}{l}585.75+ \\
200.47\end{array}$ & $64.5+5.0$ & & $152.5+30.65$ & $1060+73$ & $16.00+3.26$ \\
\hline $\mathrm{MIP}-1 \mathrm{a} / \mathrm{CCL} 3$ & $47+4$ & & $12.5+0.5$ & $29,337+2030$ & $27.25+5.12$ & $531+37$ & $1.59+0.24$ \\
\hline MIP-1ß/CCL4 & $51+5$ & & $134.9+2.3$ & $17,087+2385$ & $124.25+33.93$ & $1641+289$ & $169.77+13.01$ \\
\hline RANTES/CCL5 & $\begin{array}{l}2,705,600+496 \\
076\end{array}$ & $\begin{array}{l}67.71+ \\
18.33\end{array}$ & $\begin{array}{l}15,810.8+ \\
717.7\end{array}$ & $\begin{array}{l}376,730+56 \\
734\end{array}$ & & $1453+24$ & $8788.00+644.50$ \\
\hline MCP3/CCL7 & & & & & $397+126.25$ & & OOR< \\
\hline Eotaxin/CCL11 & & & $72.6+3.3$ & & $91.5+31.2$ & $196+64$ & $44.68+5.86$ \\
\hline CTACK/CCL27 & & & & & & & $311.83+44.73$ \\
\hline MSP/MST1 & & & & $\begin{array}{l}688,589+132, \\
037\end{array}$ & & & \\
\hline MDC & & & & & $470.25+300.42$ & & \\
\hline MIF & & & & $\begin{array}{l}287,188+51 \\
282\end{array}$ & & & $6645.36+768.15$ \\
\hline LIF & & & & & & $1473+114$ & $79.47+18.88$ \\
\hline GROa/CXCL1 & $11,126+6480$ & & & $40,947+3148$ & & $866+109$ & $1203.04+98.03$ \\
\hline IL-8/CXCL8 & $80+6$ & $17.15+5.22$ & $112.5+5.3$ & & $57+16.53$ & ND & $21.98+3.82$ \\
\hline MIG/CXCL9 & & & & & & & $96.33+8.36$ \\
\hline IP-10/CXCL10 & & & $284.7+3.1$ & & $82.5+33.37$ & $527+65$ & $384.76+11.42$ \\
\hline SDF1a/CXCL12 & & & & & & $16,102+1506$ & $753.49+49.21$ \\
\hline
\end{tabular}


Table 1 Multiplex-based measurements of cytokine concentrations $(\mathrm{pg} / \mathrm{mL})$ in HPL (Continued)

\begin{tabular}{|c|c|c|c|c|c|c|c|}
\hline Reference & $(21)^{*}$ & (39) & (41) & (42) & (43) & $(44)^{* *}$ & Present study \\
\hline IL-1a & $41+6$ & $\begin{array}{l}88.78+ \\
33.30\end{array}$ & & $4854+533$ & $39.25+18.44$ & ND & \\
\hline$I L-1 \beta$ & $3+2$ & $24.89+9.22$ & $6.7+0.4$ & & $4.47+1.77$ & ND & $2.82+0.39$ \\
\hline IL-1ra & & & $235.3+4.8$ & $3997+589$ & $717.25+283.94$ & $10,580+605$ & \\
\hline IL-2 & OOR< & & $\mathrm{OOR}<$ & & $4.92+2.59$ & ND & OOR< \\
\hline IL-2ra & & & & & & & $209.18+81.59$ \\
\hline IL-3 & & & & & $4.97+1.55$ & & OOR< \\
\hline $\mid \mathrm{L}-4$ & & & $14.2+0.5$ & $3840+639$ & $30.75+12.91$ & ND & OOR< \\
\hline IL-5 & & & $\mathrm{OOR}<$ & & $53.25+26.34$ & ND & $180.33+67.29$ \\
\hline IL-6 & $3+0$ & $\begin{array}{l}159.75+ \\
61.57\end{array}$ & $22.5+0.6$ & & $9+4.42$ & $1847+178$ & $54.19+21.40$ \\
\hline IL-7 & $32+16$ & & $41.8+1.1$ & & $27+7.39$ & $145+24$ & $31.43+5.57$ \\
\hline IL-9 & & & $129.9+6.3$ & & $6.9+2.5$ & $942+49$ & $208.42+20.72$ \\
\hline $\mid \mathrm{L}-10$ & $3+2$ & & $60.2+2.4$ & & $10.85+7.74$ & $186+25$ & $\mathrm{OOR}<$ \\
\hline IL-12(p40) & & & & & $51.5+13.91$ & & $135.82+25.12$ \\
\hline IL-12(p70) & & & $113.9+5.1$ & & $8.85+3.08$ & ND & $12.85+4.61$ \\
\hline IL-13 & & & $7.7+1.1$ & & $291+131.16$ & ND & OOR< \\
\hline IL-15 & & & $\mathrm{OOR}<$ & & $7.7+3.52$ & $568+29$ & $689.27+228.99$ \\
\hline IL-17 & & & $1022.5+56.4$ & & $10.87+4.04$ & $622+91$ & $11.25+1.76$ \\
\hline IL-18 & & & & & & $2466+349$ & $34.37+11.56$ \\
\hline $\mid \mathrm{LL}-21$ & & & & & & ND & \\
\hline IL-22 & & & & & & ND & \\
\hline IL-23 & & & & & & ND & \\
\hline IL-27 & & & & & & $2658+1053$ & \\
\hline $\mid \mathrm{LL}-31$ & & & & & & ND & \\
\hline TNF-a & $8+2$ & $\begin{array}{l}427.25+ \\
167.01\end{array}$ & $133.3+10.4$ & & $20.25+5.56$ & $2942+0$ & $46.97+5.8$ \\
\hline TNF- $\beta$ & & & & & $390.5+164.81$ & ND & $246.03+25.05$ \\
\hline TRAIL/TNFSF10 & & & & & & & $86.28+5.33$ \\
\hline $\mathrm{IFN}-\gamma$ & $14+4$ & $6.61+2.27$ & $154.6+7.4$ & & $12.125+2.59$ & ND & $23.41+3.19$ \\
\hline IFN-a2 & & & & & $63.25+19.72$ & $64+40$ & $8.44+1.29$ \\
\hline VCAM-1 & $\begin{array}{l}1,789,695+1,108 \\
320\end{array}$ & & & & & & \\
\hline ICAM-1 & $137,300+93,670$ & & & & & & \\
\hline Angiopoietin-1 & & & & $\begin{array}{l}121,156+22 \\
164\end{array}$ & & & \\
\hline Angiogenin & & & & $\begin{array}{l}102,085+17 \\
627\end{array}$ & & & \\
\hline IGFBP3 & & & & $\begin{array}{l}530,240+75 \\
663\end{array}$ & & & \\
\hline CD40L & $29,738+8361$ & & & $\begin{array}{l}151,662+17 \\
153\end{array}$ & & & \\
\hline TIMP-1 & & & & $\begin{array}{l}231,407+39, \\
966\end{array}$ & & & \\
\hline
\end{tabular}

$B C$ buffy coats, $A P$ apheresis, $P I$ pathogen inactivated, $F / T$ freeze/thaw cycles, $d$ days, $w$ weeks, OOR out of range Data represent means $\pm S D$

*No significant differences between buffy coat- and apheresis-derived HPL

${ }^{*}$ Cytokine concentrations in medium supplemented with $10 \% \mathrm{HPL}$ 


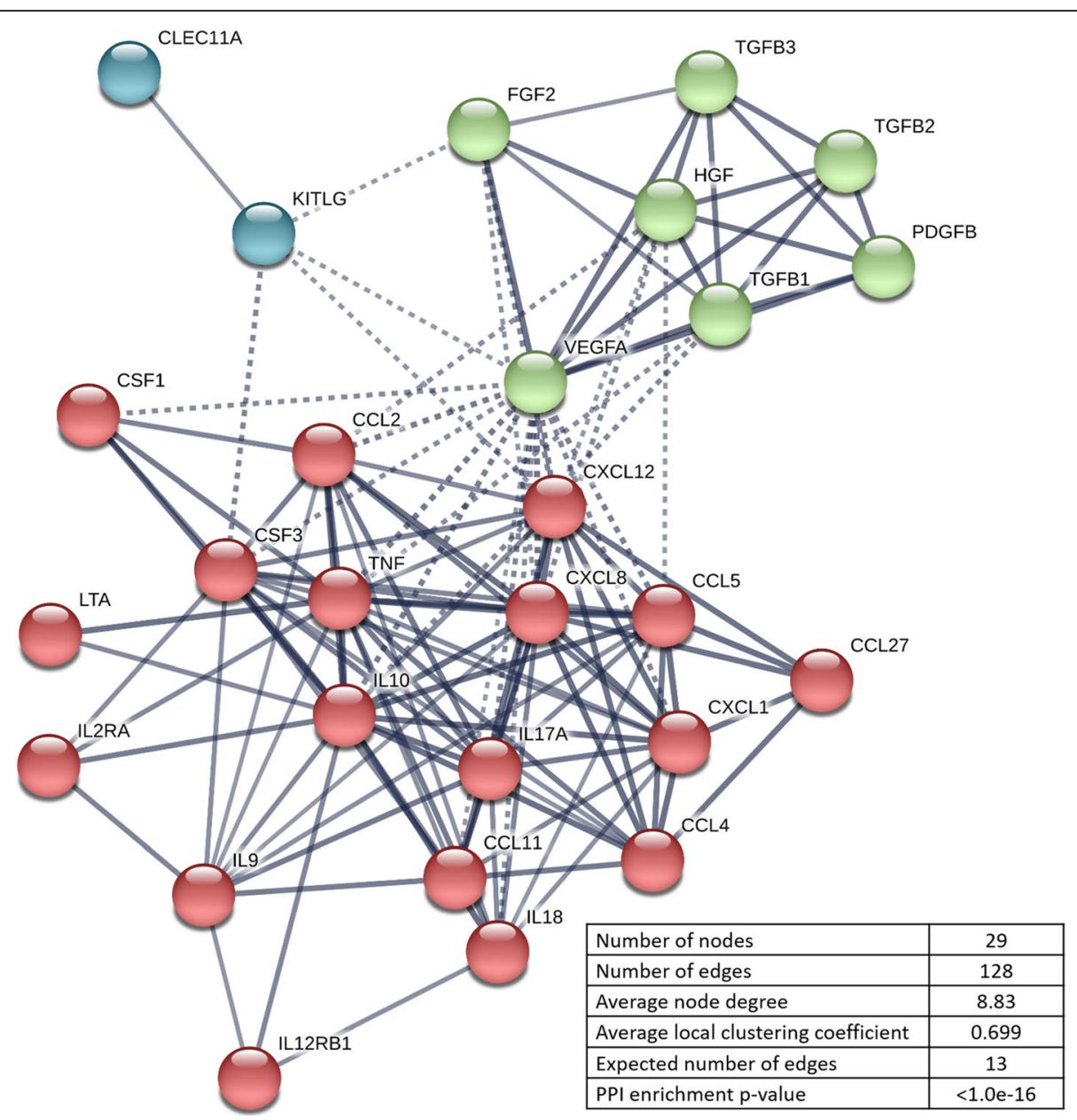

Fig. 3 Protein-protein interaction network visualized by STRING. The nodes indicate proteins, and edges indicate the number of interactions. Color saturation of the edges represents the confidence score of a functional association. The number of average interactions per node is indicated by the node degree. The clustering coefficient specifies the average node density of the map. Disconnected nodes are hidden, and only interactions with a high confidence score of $\geq 0.7$ are shown

i.e., BMSCs and ASCs, to evaluate HPL efficacy. Moreover, MSCs from each tissue type were cultured in HPLand FBS-supplemented media from the time of isolation (passage 0), thus allowing true and standardized comparisons between xeno-free and xenogeneic-cultured cells [23]. Since the focus herein was BTE, the in vitro osteogenic differentiation of BMSCs and ASCs was studied in detail and was shown to be significantly enhanced in HPL vs. FBS at the early (expression of osteogenic genes), intermediate (ALP activity) and late stages (mineral deposition). Moreover, a trend for higher expression of STRO-1, a marker associated increased osteogenic potential [24], was observed in HPL- vs. FBS-cultured BMSCs and ASCs. When comparing the two cell types, osteogenic differentiation appeared to be accelerated in HPL-cultured BMSCs vs. ASCs, based on gene expression and ALP activity during the "early" differentiation stages, while adipogenic differentiation of HPL-cultured
ASCs was superior to that of BMSCs. One possible explanation could be the "tissue source variability" of BMSCs and ASCs $[17,25]$. In context, previous studies have reported similar or enhanced differentiation of ASCs compared to BMSCs in vitro, but inferior bone formation in vivo, in both xenogeneic $[26,27]$ and HPLsupplemented cultures [28].

A substantial body of evidence points to the enhanced osteogenic potential of MSCs cultured in HPL [29-36], although the specific components contributing to this phenomenon are unknown. In the present study, the cytokine content of HPL was analyzed via a quantitative multiplex immunoassay to identify potentially relevant cytokines contributing to MSC osteogenesis. Although previous studies have measured cytokines in HPL via semi-quantitative assays [22, 36-40], to our knowledge, only five studies have reported quantitative multiplexbased assessments [21, 39, 41-44]. Considerable 


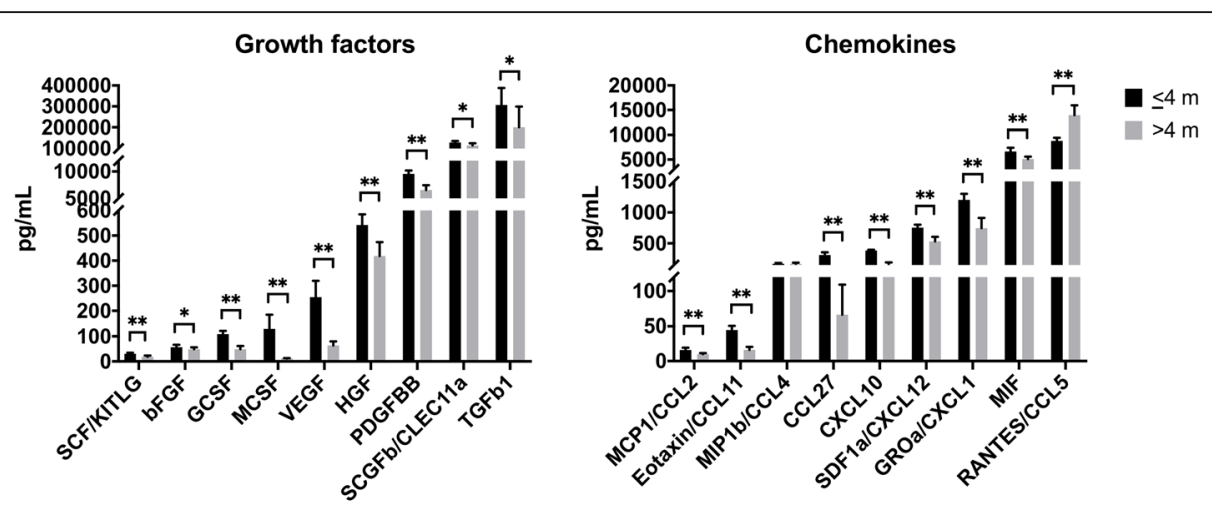

Inflammatory markers

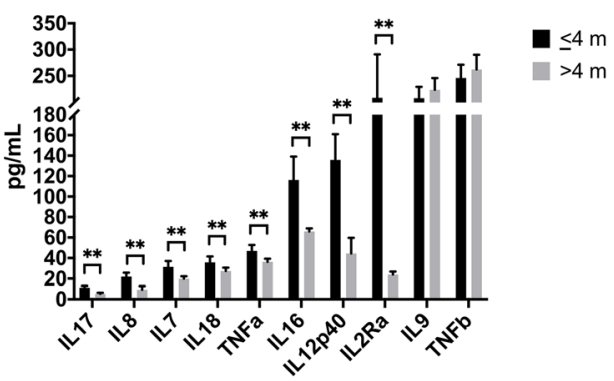

Fig. 4 Cytokine concentrations in HPL from PCs stored for $\leq 4$ or $>4$ [5-9] months (m). Data represent means \pm SD ( $n=12$ HPL batches per group). ${ }^{*} p<0.05,{ }^{* *} p<0.001$

differences in cytokine concentrations are observed across the different studies (Table 1). Moreover, it is presently unclear which cytokines in HPL are most important, what are the optimal (minimum and/or maximum) concentrations of specific cytokines, and what are the effects of HPL preparation methods on individual cytokine concentrations [10]. Nevertheless, some cytokines such as PDGF-BB, TGF- $\beta 1$, and b-FGF have been consistently identified in HPL in substantial quantities. A previous study identified PDGF-BB, TGF- $\beta 1$, and bFGF to be necessary for the optimal proliferation of MSCs in HPL [21]. However, these three factors on their own were not sufficient to promote MSC proliferation [21]. These data are consistent with findings that combinations of cytokines, rather than single GFs, are important to exert maximal effects on MSC migration and proliferation [45]. However, in another study, even the use of defined combinations of several recombinant GFs and chemokines was inferior to HPL supplementation for MSC expansion [46]. Since measurement of selected cytokine concentrations has been cited as a "quality control" measure for GMP-grade HPL [12], further information is needed on which cytokines (for specific MSC applications, e.g., BTE) should be tested along with "target" concentration ranges.

In addition to established factors such as PDGF-BB and TGF- $\beta 1$, high concentrations of stem cell growth factor (SCGF) - a cytokine not previously identified in HPL-were detected in the multiplex analysis herein. SCGF is a protein encoded by the CLEC11A gene (Ctype lectin domain family 11 , member A) and is associated with the growth of hematopoietic progenitor cells [47]. In the context of the bone, SCGF/CLEC11A is reportedly expressed in the bone marrow by a variety of stromal cells $[47,48]$. Interestingly, CLEC11A was recently shown to be expressed by murine BMSCs, and its overexpression promoted their in vitro osteogenic differentiation and in vivo osteogenesis in a fracture healing model [47]. However, a more recent study showed contrasting results in human BMSCs, where silencing, rather than overexpression, of CLEC11A promoted their in vitro osteogenic differentiation [49]. In another study, SCGF was detected in the secretome of BMSCs undergoing osteogenic differentiation and was found to be downregulated on days 1,7 , and 14 compared to day 0 [50]. Thus, in addition to PDGF-BB and TGF- $\beta 1$, SCGF/ CLEC11A signaling may be involved in the regulation of osteogenic differentiation of HPL-cultured MSCs.

Consistent with results from the above study [49], the in silico network analysis herein identified only a single interaction for SCGF/CLEC11A, which was with the chemokine stem cell factor (SCF), a ligand for the c-kit receptor (KITLG) [51]. Like SCGF, SCF is also typically associated with hematopoietic cell proliferation [51]. 


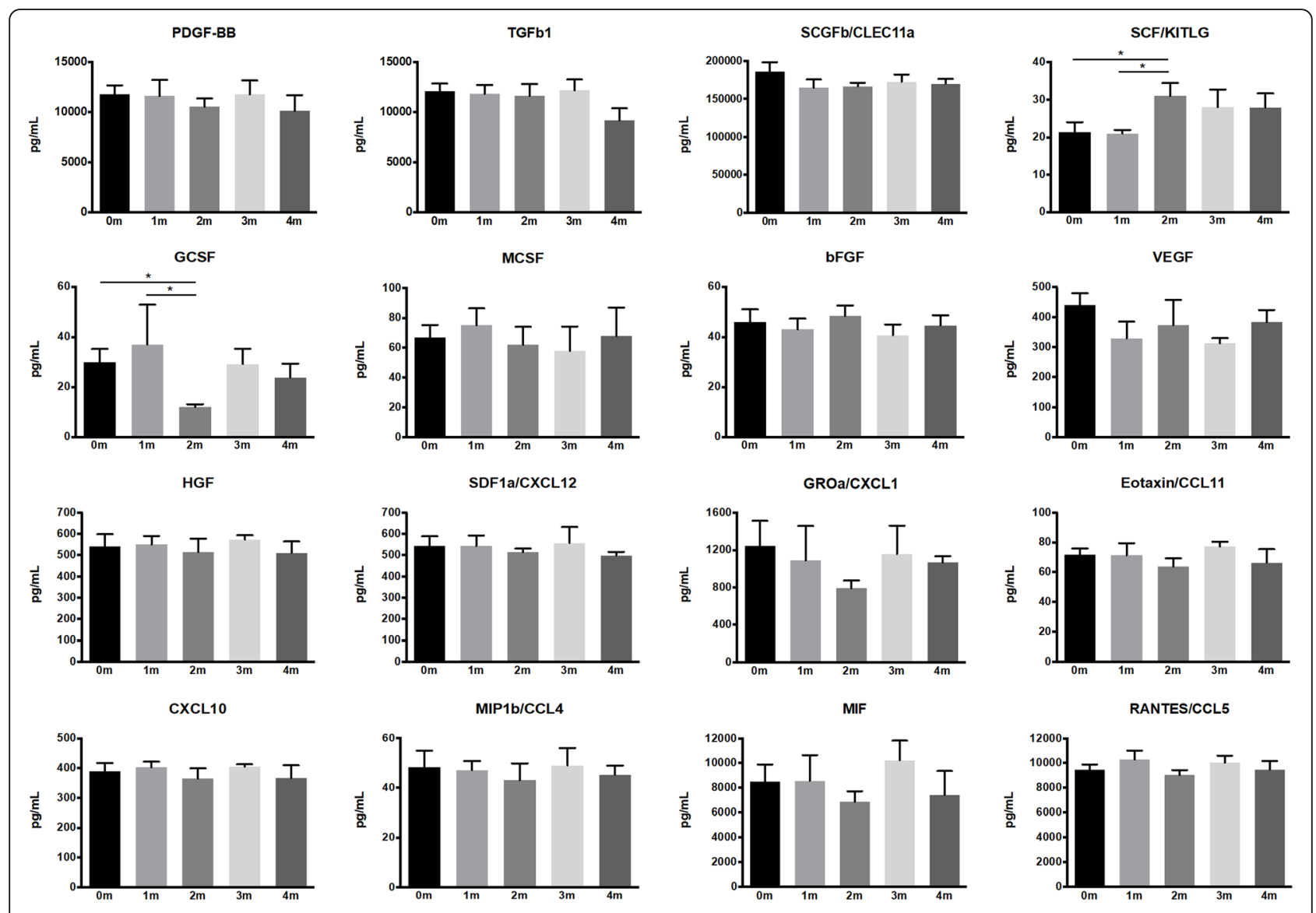

Fig. 5 Cytokine concentrations in HPL from PCs stored for $0-4$ months (m). Data represent means \pm SD ( $n=\geq 3$ HPL batches per group). ${ }^{*} p<0.05$

Although SCF was detected at a relatively lower concentration compared to SCGF, the network analysis revealed several interactions with the cytokine/chemokine and GF clusters. Recently, SCF signaling has been implicated in the mobilization, and subsequent osteogenic differentiation, of BMSCs in vitro and in in vivo models of fracture healing [52] and dental pulp/dentin regeneration [53]. Further studies are needed to elucidate the nature of the interaction(s) between SCGF, SCF, and other cytokines in the context of MSCs' osteogenic differentiation.

In addition to GFs, HPL also contains a wide range of chemokines, which regulate MSC migration, proliferation, and differentiation. Several chemokines of the CCL and CXCL families have been identified in HPL (Table 1). Of these, stromal derived factor-1 (SDF-1/ CXCL12) is the most extensively studied and is involved in the recruitment of endogenous BMSCs to injury sites [54]. Platelets have been shown to release SDF1 and recruit progenitor cells to initiate wound healing at sites of vascular injury [55]. In the context of the bone, SDF1 was shown to play a critical role in the recruitment of murine BMSCs to the injury site during the early stages of fracture healing, and inhibition of SDF1 led to reduced in vivo bone formation [56]. Moreover, SDF1 regulated BMP2-induced osteogenic differentiation of mouse and human BMSCs; blocking SDF1 signaling led to significantly reduced ALP activity and mineralization of the cells [57]. Recent studies have also demonstrated enhanced in vivo bone regeneration following delivery of SDF1 via recruitment of endogenous MSCs to regeneration sites [58-61], thus highlighting the role of SDF1 in regulating MSCs' osteogenic differentiation.

Emerging evidence suggests that MSCs exert their regenerative effects primarily via paracrine mechanisms and modulation of immune cells, including osteoclasts [62]. Osteoblast-osteoclast interactions are known to be critical for bone regeneration. This is especially relevant in BTE, where MSCs are often delivered using biomaterial scaffolds, which elicits an initial inflammatory/resorptive response by macrophages/osteoclasts prior to bone formation by MSCs/osteoblasts [63]. It is therefore also of interest to consider the cytokines in HPL that may be involved in the regulation of osteoclastic activity. The most consistently reported of these are RANTES/ CCL5 and associated cytokines, monocyte chemotactic protein-1 (MCP-1/CCL2), macrophage inflammatory protein 1 (MIP-1 $\alpha / C C L 3$ and MIP- $\beta / C C L 4)$, and macrophage migration inhibitory factor (MIF). All of these 

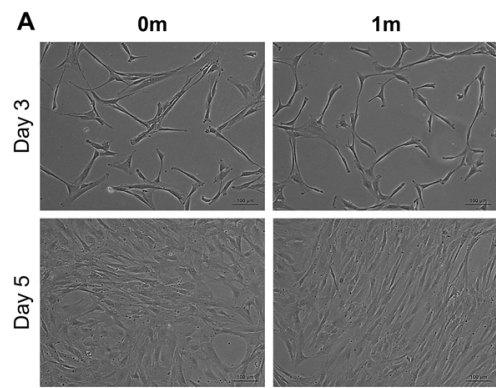

B

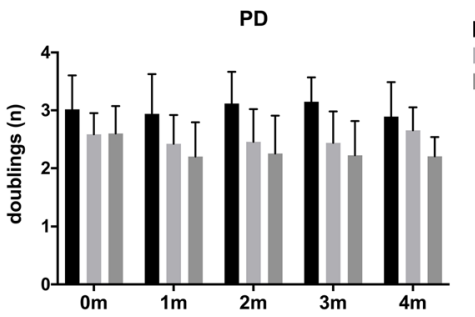

CPD

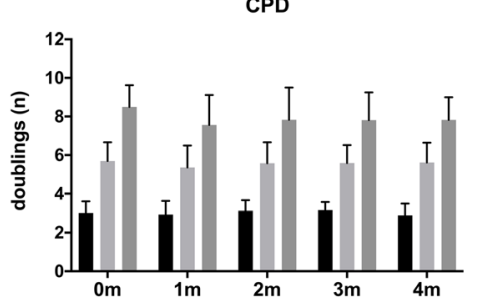

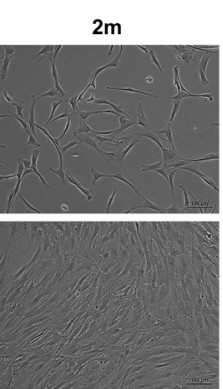
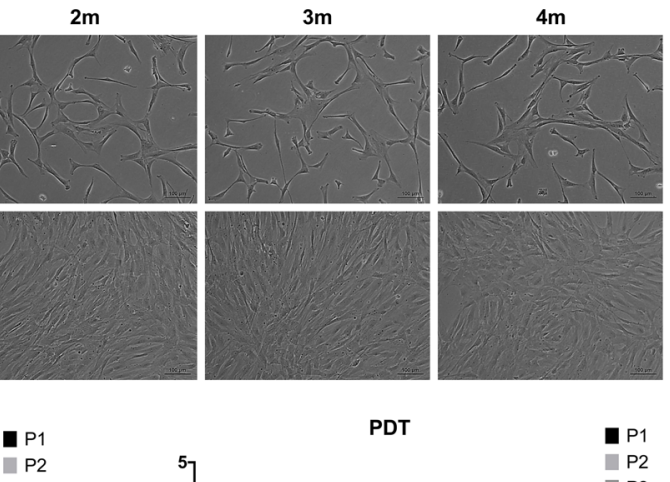

$\mathrm{P} 2$
$\mathrm{P} 3$

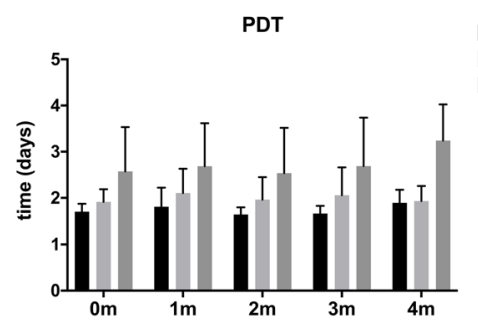

D1

$\mathrm{P} 2$
$\mathrm{P} 3$

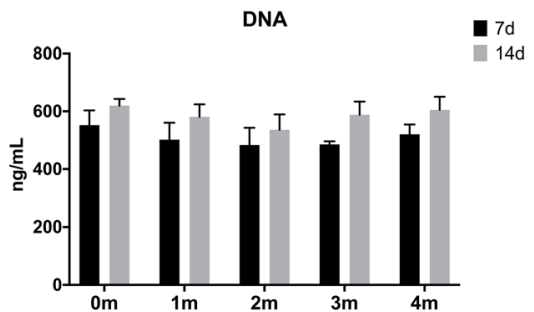

Fig. 6 Morphology and proliferation kinetics of BMSCs in HPL from PCs stored for 0-4 months (m). a Morphology of BMSCs at passage 2 (representative images from one donor), scale bar $100 \mu \mathrm{m}$. b Proliferation kinetics over three serial passages (P1-3) and DNA content after 7 and 14 days (d). Data represent means \pm SD ( $n=\geq 4$ donors). PD, population doubling rate; CPD, cumulative population doublings; PDT, population doubling time

have been implicated in the recruitment and differentiation of osteoclasts and/or their precursors [64-66]. Moreover, it has been demonstrated that RANTES secreted by osteoclasts promotes the migration of osteoblasts and MSCs in vitro $[64,67,68]$ and mineralization in vivo $[68,69]$.

In addition to GFs and chemokines, a number of inflammatory cytokines were identified in the HPL herein. The evidence for the effects of inflammatory cytokines on MSCs is conflicting since these effects appear to be (a) tissue/site-specific, (b) MSC type-specific, and (c) dosedependent, based on which a particular cytokine may exert pro- or anti-inflammatory and pro- or antiosteogenic effects [54]. The most commonly reported of these are TNF- $\alpha$ and IL-1, predominant during the acute inflammatory phase of healing. The combination of HPL and exogenous IL- $1 \alpha$ was shown to result in a transient increase in the inflammatory response accompanied by an increase in proliferation, without loss of differentiation potential, in human osteoblasts [70] and ASCs [71]. Interferon- $\gamma$ (IFN- $\gamma$ ), another major pro-inflammatory cytokine, has consistently more anti-osteogenic effects [54]. Nevertheless, several studies have reported advantages of "pre-conditioning" MSCs with IFN- $\gamma$, either alone or in combination with other cytokines such as TNF- $\alpha$ and IL-1, in terms of their immunomodulatory and regenerative potential [72].

Recent studies have reported differences in MSC proliferation and osteogenic differentiation when cultured in different HPL formulations, expressing differences in their protein compositions [15, 73]. MSC proliferation, i.e., PD rate/time, is considered a "key parameter" during ex vivo expansion [11], and ALP and mineralization assays are routinely used to test the in vitro osteogenic capacity of MSCs. In the context of BTE, the in vitro PD time and ALP activity of MSCs are reported to most likely correlate with their in vivo mineralization capacity [74]. Accordingly, in the present study, the growth kinetics and osteogenic potential of BMSCs were tested in HPLs produced from the different PC storage times; BMSCs from multiple donors were used to account for donor-related variations. No significant differences were observed between the different PC storage times in terms of either BMSC proliferation or ALP activity/ mineralization. However, considerable donor-related variation was observed in relation to the latter. Notably, the highest relative mean ALP activity and mineralization, with the 

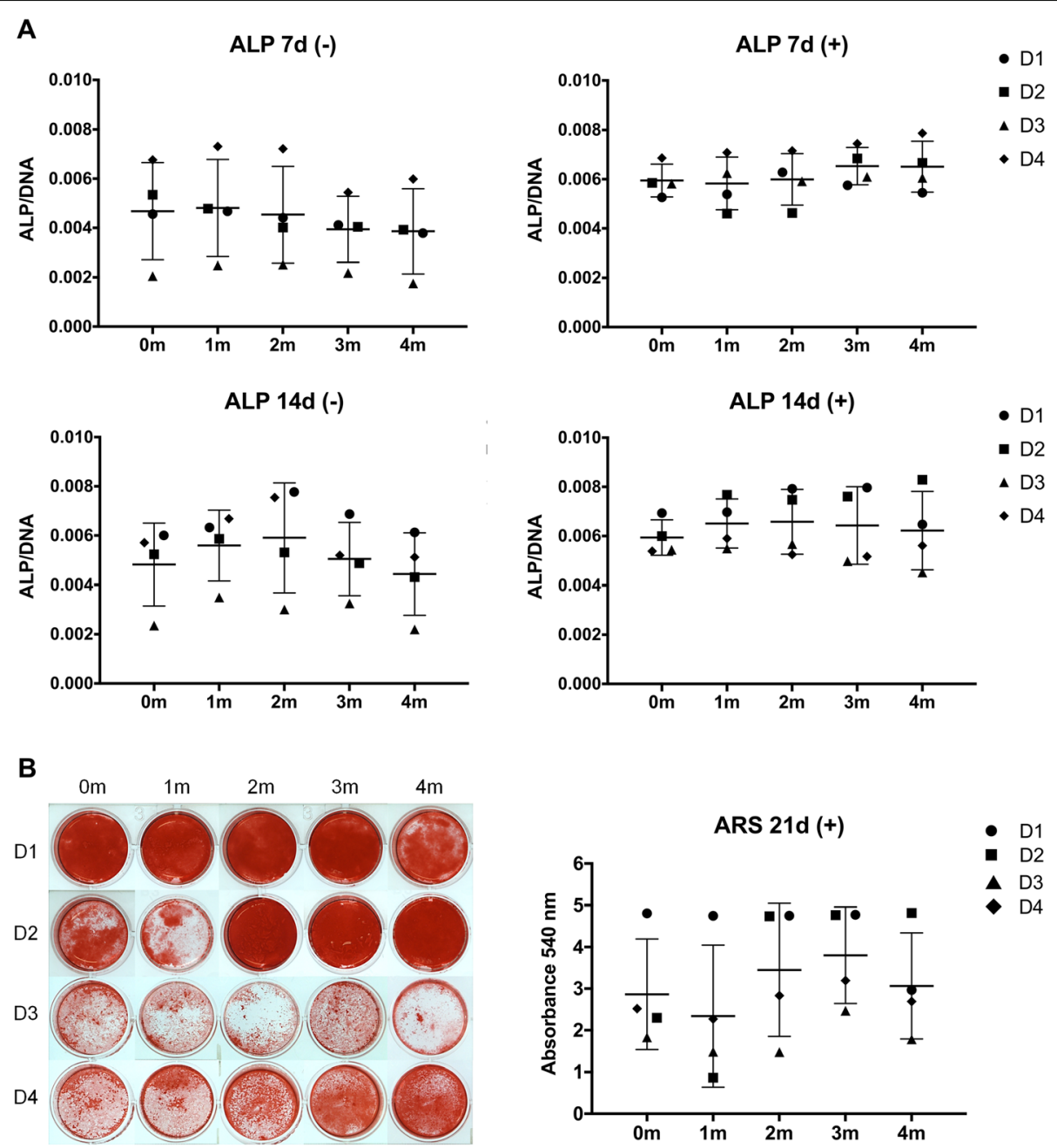

Fig. 7 Osteogenic differentiation of BMSCs in HPL from PCs stored for 0-4 months (m). a ALP activity at 7 and 14 days (d) in osteogenic (+) and standard (-) HPL media. ALP activity (absorbance) was normalized to the corresponding DNA content (ng/mL). b Representative images and quantification of Alizarin Red S (ARS)-stained cells after 21 days of induction. Data represent means \pm SD; each symbol represents a single donor ( $D, n=4$ donors) based on the average of 3 experimental replicates

least inter-donor variation, was observed in the 3-month PC storage group. The results herein are consistent with a recent study reporting on MSCs from a similar donor cohort (healthy young patients), which reported large inter-donor variations in xenogeneic MSCs [17]. It is well-known that several biological (age, sex), behavioral (alcohol/tobacco use), and disease-related (obesity, diabetes) factors influence MSC properties including proliferation and osteogenic differentiation [75]. Nevertheless, it must be acknowledged that the observed donor variation may have confounded the detection of significant differences between PC storage times in the present study.

Among various aspects of HPL production which require standardization is the storage time of the source material, i.e., PCs produced by blood establishments. Current recommendations call for blood centers to freeze outdated PCs (within 7 days of collection) for later
HPL production, although "the maximum period time that PCs can be used after expiry to prepare an efficient HPL for cell expansion is unknown" [9]. International blood authorities advise a minimum interval of 3 months between blood donations to allow for repeated viral testing to minimize the risk of disease transmission via platelet products. In the context of HPL, this is especially relevant when smaller PC-pool sizes are used $(\leq 16$ donors) and where pathogen reduction is not applied [6]. In the present study, HPL produced from PCs stored for $>4$ months showed a significant deterioration of several cytokines relevant for MSCs. No significant differences between PC storage times $<4$ months were observed in terms of HPL cytokine concentrations, i.e., a clear trend for cytokine deterioration with time, or corresponding MSC proliferation and osteogenic differentiation. Thus, the data herein did not allow for the 
detection of any statistical associations between specific HPL cytokines and the degree of MSC osteogenic differentiation. Nevertheless, our observation that outdated PCs can be safely frozen for up to 4 months (preferably 3 months when the focus is BTE) may facilitate the implementation of routines enabling more blood banks to produce HPL. This would address the need for standardization and scaling-up of HPL production, while also benefiting blood bank economies.

\section{Conclusions}

The expansion of human MSCs in HPL represents a favorable strategy for BTE. MSCs expanded in HPL demonstrate a high in vitro osteogenic differentiation potential, albeit with considerable donor variation. Exactly which components of HPL contribute to enhancing the osteogenic potential of MSCs is unclear, since HPL contains a complex mixture of cytokines, chemokines, and inflammatory mediators presenting with synergistic effects. Based on the proteomic analysis herein, further investigation of the role of certain cytokines, particularly SCGF, in the regulation of MSCs' osteogenic differentiation is warranted. Finally, a maximum frozen storage time of 4 months is recommended for outdated PCs assigned for HPL production at blood establishments.

\section{Supplementary information}

Supplementary information accompanies this paper at https://doi.org/10. 1186/s13287-020-01863-9.

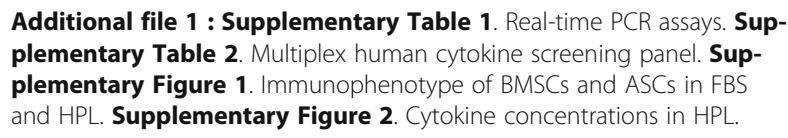

\begin{abstract}
Abbreviations
BTE: Bone tissue engineering; MSCs: Mesenchymal stromal cells; BMSCs: Bone marrow-derived mesenchymal stromal cells; ASCs: Adipose tissue-derived mesenchymal stromal cells; SVF: Stromal vascular fraction; GMP: Good manufacturing practice; FBS: Fetal bovine serum; HPL: Human platelet lysate; PCs: Platelet concentrates; qPCR: Quantitative real-time polymerase chain reaction; ELISA: Enzyme-linked immunosorbent assay; ALP: Alkaline phosphatase; GFs: Growth factors; PD: Population doubling rate; PDT: Population doubling time; CPD: Cumulative population doubling
\end{abstract}

\section{Acknowledgements}

We thank the Bloodbank at Haukeland University Hospital for supplying the platelet concentrates, the technical staff at the Department of Clinical Dentistry for assisting in the preparation of platelet lysates, and Prof. Stein Atle Lie for the statistical assistance with the study.

\section{Authors' contributions}

S.S. designed the study, performed the experiments, analyzed the data, and drafted the manuscript. S.M.A., T.H.F.L., and S.S. contributed to the design, experiments, data analysis, and manuscript writing. A.I.B., T.H., and K.M. contributed to the design, data analysis, and manuscript writing. The authors read and approved the final manuscript.

\section{Funding}

This work was supported by Helse Vest Strategic Research Funding, Norway (502027); Research Council of Norway (BEHANDLING/273551); and the Trond Mohn Foundation, Norway (BFS2018TMT10).

Availability of data and materials

Additional data can be made available by the authors upon request.

Ethics approval and consent to participate

Ethical approval for the collection and use of the human tissue samples was obtained from the Regional Committees for Medical and Health Research Ethics (REK) in Norway (reference number 2013/1248/REK sør-øst C).

Consent for publication

Not applicable.

\section{Competing interests}

The authors confirm that there are no known conflicts of interest associated with this publication and there has been no significant financial support for this work that could have influenced its outcome.

\section{Author details}

${ }^{1}$ Department of Clinical Dentistry, Faculty of Medicine, University of Bergen, Årstadveien 19, 5008 Bergen, Norway. ${ }^{2}$ Department of Immunology and Transfusion Medicine, Haukeland University Hospital, Bergen, Norway. ${ }^{3}$ Laboratory of Immunology and Transfusion Medicine, Haugesund Hospital, Fonna Health Trust, Haugesund, Norway. ${ }^{4}$ Department of Clinical Science, University of Bergen, Bergen, Norway.

Received: 3 March 2020 Revised: 25 June 2020

Accepted: 29 July 2020 Published online: 23 September 2020

\section{References}

1. Shanbhag S, Suliman S, Pandis N, Stavropoulos A, Sanz M, Mustafa K. Cell therapy for orofacial bone regeneration: a systematic review and metaanalysis. J Clin Periodontol. 2019;46(Suppl 21):162-82.

2. Prins HJ, Schulten EAJM, Ten Bruggenkate CM, Klein-Nulend J, Helder MN. Bone regeneration using the freshly isolated autologous stromal vascular fraction of adipose tissue in combination with calcium phosphate ceramics. Stem Cell Transl Med. 2016;5(10):1362-74.

3. Karnieli O, Friedner OM, Allickson JG, Zhang N, Jung S, Fiorentini D, et al. A consensus introduction to serum replacements and serum-free media for cellular therapies. Cytotherapy. 2017;19(2):155-69.

4. Shanbhag S, Stavropoulos A, Suliman S, Hervig T, Mustafa K. Efficacy of humanized mesenchymal stem cell cultures for bone tissue engineering: a systematic review with a focus on platelet derivatives. Tissue Eng Part B Rev. 2017:23(6):552-69.

5. Mendicino M, Bailey AM, Wonnacott K, Puri RK, Bauer SR. MSC-based product characterization for clinical trials: an FDA perspective. Cell Stem Cell. 2014;14(2):141-5.

6. Bieback K, Fernandez-Munoz B, Pati S, Schafer R. Gaps in the knowledge of human platelet lysate as a cell culture supplement for cell therapy: a joint publication from the AABB and the International Society for Cell \& Gene Therapy. Transfusion. 2019;59(11):3448-60.

7. European Medicines Agency. Guideline on the use of bovine serum in the manufacture of human biological medicinal products. EMA/CHMP/BWP/ 457920/2012 rev 1. Amsterdam: European Medicines Agency; 2013.

8. Phinney DG, Galipeau J, Msc Committee of the International Society of C, Gene T. Manufacturing mesenchymal stromal cells for clinical applications: a survey of good manufacturing practices at U.S. academic centers. Cytotherapy. 2019;21 (7):782-92.

9. Schallmoser K, Henschler R, Gabriel C, Koh MBC, Burnouf T. Production and quality requirements of human platelet lysate: a position statement from the working party on cellular therapies of the International Society of Blood Transfusion. Trends Biotechnol. 2020:38(1):13-23.

10. Burnouf T, Strunk D, Koh MB, Schallmoser K. Human platelet lysate: replacing fetal bovine serum as a gold standard for human cell propagation? Biomaterials. 2016;76:371-87.

11. Rojewski MT, Lotfi R, Gjerde C, Mustafa K, Veronesi E, Ahmed AB, et al. Translation of a standardized manufacturing protocol for mesenchymal 
stromal cells: a systematic comparison of validation and manufacturing data. Cytotherapy. 2019;21(4):468-82.

12. Henschler R, Gabriel C, Schallmoser K, Burnouf T, Koh MBC. Human platelet lysate current standards and future developments. Transfusion. 2019;59(4): 1407-13.

13. Strunk D, Lozano M, Marks DC, Loh YS, Gstraunthaler G, Schennach H, et al. International Forum on GMP-grade human platelet lysate for cell propagation. Vox Sang. 2018;113(1):e1-e25.

14. Strunk D, Lozano M, Marks DC, Loh YS, Gstraunthaler G, Schennach H, et al. International Forum on GMP-grade human platelet lysate for cell propagation: summary. Vox Sang. 2018;113(1):80-7.

15. Boraldi F, Burns JS, Bartolomeo A, Dominici M, Quaglino D. Mineralization by mesenchymal stromal cells is variously modulated depending on commercial platelet lysate preparations. Cytotherapy. 2018;20(3):335-42.

16. Schallmoser K, Strunk D. Generation of a pool of human platelet lysate and efficient use in cell culture. Methods Mol Biol. 2013;946:349-62.

17. Mohamed-Ahmed S, Fristad I, Lie SA, Suliman S, Mustafa K, Vindenes H, et al. Adipose-derived and bone marrow mesenchymal stem cells: a donormatched comparison. Stem Cell Res Ther. 2018;9(1):168.

18. Dominici M, Le Blanc K, Mueller I, Slaper-Cortenbach I, Marini F, Krause D, et al. Minimal criteria for defining multipotent mesenchymal stromal cells. The International Society for Cellular Therapy position statement. Cytotherapy. 2006:8:315-7.

19. Szklarczyk D, Gable AL, Lyon D, Junge A, Wyder S, Huerta-Cepas J, et al. STRI NG v11: protein-protein association networks with increased coverage, supporting functional discovery in genome-wide experimental datasets. Nucleic Acids Res. 2019;47(D1):D607-D13.

20. Munir A, Døskeland A, Avery SJ, Fuoco T, Mohamed-Ahmed S, Lygre H, et al. Efficacy of copolymer scaffolds delivering human demineralised dentine matrix for bone regeneration. J Tissue Eng. 2019;10: 2041731419852703.

21. Fekete N, Gadelorge M, Furst D, Maurer C, Dausend J, Fleury-Cappellesso S, et al. Platelet lysate from whole blood-derived pooled platelet concentrates and apheresis-derived platelet concentrates for the isolation and expansion of human bone marrow mesenchymal stromal cells: production process, content and identification of active components. Cytotherapy. 2012;14(5):540-54.

22. Bieback K, Hecker A, Kocaomer A, Lannert H, Schallmoser K, Strunk D, et al. Human alternatives to fetal bovine serum for the expansion of mesenchymal stromal cells from bone marrow. Stem Cells. 2009;27(9):2331-41.

23. Suliman S, Ali HRW, Karlsen TA, Amiaud J, Mohamed-Ahmed S, Layrolle P, et al. Impact of humanised isolation and culture conditions on stemness and osteogenic potential of bone marrow derived mesenchymal stromal cells. Sci Rep. 2019;9(1):16031.

24. Gronthos S, Graves SE, Ohta S, Simmons PJ. The STRO-1+ fraction of adult human bone marrow contains the osteogenic precursors. Blood. 1994; 84(12):4164-73.

25. Xu L, Liu Y, Sun $Y$, Wang B, Xiong $Y$, Lin W, et al. Tissue source determines the differentiation potentials of mesenchymal stem cells: a comparative study of human mesenchymal stem cells from bone marrow and adipose tissue. Stem Cell Res Ther. 2017;8(1):275

26. Fennema EM, Tchang LAH, Yuan H, van Blitterswijk CA, Martin I, Scherberich $A$, et al. Ectopic bone formation by aggregated mesenchymal stem cells from bone marrow and adipose tissue: a comparative study. J Tissue Eng Regen Med. 2018;12(1):e150-e8.

27. Brocher J, Janicki $P$, Voltz $P$, Seebach E, Neumann E, Mueller-Ladner U, et al. Inferior ectopic bone formation of mesenchymal stromal cells from adipose tissue compared to bone marrow: rescue by chondrogenic pre-induction. Stem Cell Res. 2013;11(3):1393-406

28. Brennan MA, Renaud A, Guilloton F, Mebarki M, Trichet V, Sensebé L, et al. Inferior in vivo osteogenesis and superior angiogenesis of human adiposederived stem cells compared with bone marrow-derived stem cells cultured in xeno-free conditions. Stem Cell Transl Med. 2018;7(3):315.

29. Castren E, Sillat T, Oja S, Noro A, Laitinen A, Konttinen YT, et al. Osteogenic differentiation of mesenchymal stromal cells in two-dimensional and threedimensional cultures without animal serum. Stem Cell Res Ther. 2015;6:167.

30. Li CY, Wu XY, Tong JB, Yang XX, Zhao JL, Zheng QF, et al. Comparative analysis of human mesenchymal stem cells from bone marrow and adipose tissue under xeno-free conditions for cell therapy. Stem Cell Res Ther. 2015;6:55

31. Xia W, Li H, Wang Z, Xu R, Fu Y, Zhang X, et al. Human platelet lysate supports ex vivo expansion and enhances osteogenic differentiation of human bone marrow-derived mesenchymal stem cells. Cell Biol Int. 2011; 35(6):639-43.

32. Chevallier N, Anagnostou F, Zilber S, Bodivit G, Maurin S, Barrault A, et al. Osteoblastic differentiation of human mesenchymal stem cells with platelet lysate. Biomaterials. 2010;31(2):270-8.

33. Kuterbekov M, Machillot $P$, Baillet $F$, Jonas AM, Glinel $K$, Picart C. Design of experiments to assess the effect of culture parameters on the osteogenic differentiation of human adipose stromal cells. Stem Cell Res Ther. 2019; 10(1):256.

34. Shansky YD, Sergeeva NS, Sviridova IK, Karalkin PA, Kirsanova VA, Akhmedova SA, et al. Human platelet lysate sustains the osteogenic/ adipogenic differentiation potential of adipose-derived mesenchymal stromal cells and maintains their DNA integrity in vitro. Cells Tissues Organs. 2019;207(3-4):149-64.

35. Cowper M, Frazier T, Wu X, Curley L, Ma MH, Mohuiddin OA, et al. Human platelet lysate as a functional substitute for fetal bovine serum in the culture of human adipose derived stromal/stem cells. Cells. 2019;8(7):724.

36. Mangum LH, Natesan S, Stone R 2nd, Wrice NL, Larson DA, Florell KF, et al. Tissue source and cell expansion condition influence phenotypic changes of adipose-derived stem cells. Stem Cells Int. 2017;2017:7108458.

37. Horn P, Bokermann G, Cholewa D, Bork S, Walenda T, Koch C, et al. Impact of individual platelet lysates on isolation and growth of human mesenchymal stromal cells. Cytotherapy. 2010;12(7):888-98.

38. Copland IB, Garcia MA, Waller EK, Roback JD, Galipeau J. The effect of platelet lysate fibrinogen on the functionality of MSCs in immunotherapy. Biomaterials. 2013;34(32):7840-50.

39. Renn TY, Kao YH, Wang CC, Burnouf T. Anti-inflammatory effects of platelet biomaterials in a macrophage cellular model. Vox Sang. 2015;109(2):138-47.

40. Canestrari E, Steidinger HR, MCSwain B, Charlebois SJ, Dann CT. Human platelet lysate media supplement supports lentiviral transduction and expansion of human T lymphocytes while maintaining memory phenotype. J Immunol Res. 2019;2019:3616120.

41. Sovkova V, Vocetkova K, Rampichova M, Mickova A, Buzgo M, Lukasova V, et al. Platelet lysate as a serum replacement for skin cell culture on biomimetic PCL nanofibers. Platelets. 2018;29(4):395-405.

42. Viau S, Lagrange A, Chabrand L, Lorant J, Charrier M, Rouger K, et al. A highly standardized and characterized human platelet lysate for efficient and reproducible expansion of human bone marrow mesenchymal stromal cells. Cytotherapy. 2019;21(7):738-54.

43. Christensen C, Jonsdottir-Buch S, Sigurjonsson O. Effects of amotosalen treatment on human platelet lysate bioactivity; 2019.

44. Laner-Plamberger S, Oeller M, Mrazek C, Hartl A, Sonderegger A, Rohde E, et al. Upregulation of mitotic bookmarking factors during enhanced proliferation of human stromal cells in human platelet lysate. J Transl Med. 2019;17(1):432.

45. Ozaki Y, Nishimura M, Sekiya K, Suehiro F, Kanawa M, Nikawa H, et al. Comprehensive analysis of chemotactic factors for bone marrow mesenchymal stem cells. Stem Cells Dev. 2007;16(1):119-29.

46. Fekete $\mathrm{N}$, Rojewski MT, Lotfi R, Schrezenmeier $\mathrm{H}$. Essential components for ex vivo proliferation of mesenchymal stromal cells. Tissue Eng Part C Methods. 2014:20(2):129-39.

47. Yue R, Shen B, Morrison SJ. Clec1 1a/osteolectin is an osteogenic growth factor that promotes the maintenance of the adult skeleton. Elife. 2016;5:e18782.

48. Ito C, Sato H, Ando K, Watanabe S, Yoshiba F, Kishi K, et al. Serum stem cell growth factor for monitoring hematopoietic recovery following stem cell transplantation. Bone Marrow Transpl. 2003;32(4):391-8.

49. Chaboya C. Elucidating the signaling pathways for the c-type lectin clec11a in human mesenchymal stromal cells. Sacramento: California State University; 2019

50. Kristensen LP, Chen L, Nielsen MO, Qanie DW, Kratchmarova I, Kassem M, et al. Temporal profiling and pulsed SILAC labeling identify novel secreted proteins during ex vivo osteoblast differentiation of human stromal stem cells. Mol Cell Proteomics. 2012;11(10):989-1007.

51. Grabarek J, Groopman JE, Lyles YR, Jiang S, Bennett L, Zsebo K, et al. Human kit ligand (stem cell factor) modulates platelet activation in vitro. J Biol Chem. 1994;269(34):21718-24.

52. Matsumoto T, li M, Nishimura H, Shoji T, Mifune $Y$, Kawamoto A, et al. Lnkdependent axis of SCF-cKit signal for osteogenesis in bone fracture healing. J Exp Med. 2010;207(10):2207-23.

53. Ruangsawasdi N, Zehnder M, Patcas R, Ghayor C, Siegenthaler B, Gjoksi B, et al. Effects of stem cell factor on cell homing during functional pulp 
regeneration in human immature teeth. Tissue Eng Part A. 2017;23(3-4): 115-23.

54. Deshpande S, James AW, Blough J, Donneys A, Wang SC, Cederna PS, et al. Reconciling the effects of inflammatory cytokines on mesenchymal cell osteogenic differentiation. J Surg Res. 2013;185(1):278-85.

55. Massberg S, Konrad I, Schurzinger K, Lorenz M, Schneider S, Zohlnhoefer D, et al. Platelets secrete stromal cell-derived factor 1alpha and recruit bone marrow-derived progenitor cells to arterial thrombi in vivo. J Exp Med. 2006; 203(5):1221-33.

56. Kitaori T, Ito H, Schwarz EM, Tsutsumi R, Yoshitomi H, Oishi S, et al. Stromal cell-derived factor 1/CXCR4 signaling is critical for the recruitment of mesenchymal stem cells to the fracture site during skeletal repair in a mouse model. Arthritis Rheum. 2009;60(3):813-23.

57. Hosogane N, Huang Z, Rawlins BA, Liu X, Boachie-Adjei O, Boskey AL, et al. Stromal derived factor-1 regulates bone morphogenetic protein 2-induced osteogenic differentiation of primary mesenchymal stem cells. Int J Biochem Cell Biol. 2010;42(7):1132-41.

58. Liu H, Li M, Du L, Yang P, Ge S. Local administration of stromal cell-derived factor-1 promotes stem cell recruitment and bone regeneration in a rat periodontal bone defect model. Mater Sci Eng C Mater Biol Appl. 2015;53: 83-94.

59. Yang F, Xue F, Guan J, Zhang Z, Yin J, Kang Q. Stromal-cell-derived factor (SDF) 1-alpha overexpression promotes bone regeneration by osteogenesis and angiogenesis in osteonecrosis of the femoral head. Cell Physiol Biochem. 2018;46(6):2561-75.

60. Ando $Y$, Ishikawa J, Fujio M, Matsushita $Y$, Wakayama H, Hibi H, et al. Stromal cell-derived factor-1 accelerates bone regeneration through multiple regenerative mechanisms. J Oral Maxillofac Surg Med Pathol. 2019; 31(4):245-50.

61. Huang J, Chi H, Chi H, Qiu L, Wang Y, Qiu Z, et al. Stromal cell-derived factor 1 promotes cell migration to enhance bone regeneration after hypoxic preconditioning. Tissue Eng Part A. 2019;25(17-18):1300-9.

62. Haumer A, Bourgine PE, Occhetta P, Born G, Tasso R, Martin I. Delivery of cellular factors to regulate bone healing. Adv Drug Deliv Rev. 2018;129:285-94.

63. Gamblin AL, Brennan MA, Renaud A, Yagita H, Lezot F, Heymann D, et al. Bone tissue formation with human mesenchymal stem cells and biphasic calcium phosphate ceramics: the local implication of osteoclasts and macrophages. Biomaterials. 2014;35(36):9660-7.

64. Yano S, Mentaverri R, Kanuparthi D, Bandyopadhyay S, Rivera A, Brown EM, et al. Functional expression of beta-chemokine receptors in osteoblasts: role of regulated upon activation, normal T cell expressed and secreted (RANT ES) in osteoblasts and regulation of its secretion by osteoblasts and osteoclasts. Endocrinology. 2005;146(5):2324-35.

65. Kim MS, Magno CL, Day CJ, Morrison NA. Induction of chemokines and chemokine receptors CCR2b and CCR4 in authentic human osteoclasts differentiated with RANKL and osteoclast like cells differentiated by MCP-1 and RANTES. J Cell Biochem. 2006:97(3):512-8.

66. Onodera S, Sasaki S, Ohshima S, Amizuka N, Li M, Udagawa N, et al. Transgenic mice overexpressing macrophage migration inhibitory factor (MIF) exhibit high-turnover osteoporosis. J Bone Miner Res. 2006;21 (6):876-85.

67. Ponte AL, Marais E, Gallay N, Langonne A, Delorme B, Herault O, et al. The in vitro migration capacity of human bone marrow mesenchymal stem cells: comparison of chemokine and growth factor chemotactic activities. Stem Cells. 2007;25(7):1737-45.

68. Liu YC, Kao YT, Huang WK, Lin KY, Wu SC, Hsu SC, et al. CCL5/RANTES is important for inducing osteogenesis of human mesenchymal stem cells and is regulated by dexamethasone. Biosci Trends. 2014;8(3):138-43.

69. Lee JS, Lee JB, Cha JK, Choi EY, Park SY, Cho KS, et al. Chemokine in inflamed periodontal tissues activates healthy periodontal-ligament stem cell migration. J Clin Periodontol. 2017:44(5):530-9.

70. Ruggiu A, Ulivi V, Sanguineti F, Cancedda R, Descalzi F. The effect of platelet lysate on osteoblast proliferation associated with a transient increase of the inflammatory response in bone regeneration. Biomaterials. 2013;34(37): 9318-30.

71. Romaldini A, Mastrogiacomo M, Cancedda R, Descalzi F. Platelet lysate activates human subcutaneous adipose tissue cells by promoting cell proliferation and their paracrine activity toward epidermal keratinocytes. Front Bioeng Biotechnol. 2018;6:203.

72. Noronha NC, Mizukami A, Caliári-Oliveira C, Cominal JG, JLM R, Covas DT, et al. Priming approaches to improve the efficacy of mesenchymal stromal cell-based therapies. Stem Cell Res Ther. 2019;10(1):131.
73. Juhl M, Tratwal J, Follin B, Sondergaard RH, Kirchhoff M, Ekblond A, et al Comparison of clinical grade human platelet lysates for cultivation of mesenchymal stromal cells from bone marrow and adipose tissue. Scand J Clin Lab Invest. 2016;76(2):93-104.

74. Janicki $P$, Boeuf $S$, Steck E, Egermann M, Kasten P, Richter W. Prediction of in vivo bone forming potency of bone marrow-derived human mesenchymal stem cells. Eur Cell Mater. 2011;21:488-507.

75. Widholz B, Tsitlakidis S, Reible B, Moghaddam A, Westhauser F. Pooling of patient-derived mesenchymal stromal cells reduces inter-individual confounder-associated variation without negative impact on cell viability, proliferation and osteogenic differentiation. Cells. 2019;8(6):633.

\section{Publisher's Note}

Springer Nature remains neutral with regard to jurisdictional claims in published maps and institutional affiliations.
Ready to submit your research? Choose BMC and benefit from:

- fast, convenient online submission

- thorough peer review by experienced researchers in your field

- rapid publication on acceptance

- support for research data, including large and complex data types

- gold Open Access which fosters wider collaboration and increased citations

- maximum visibility for your research: over $100 \mathrm{M}$ website views per year

At $\mathrm{BMC}$, research is always in progress.

Learn more biomedcentral.com/submissions 